\title{
GAMES DAUGHTERS AND PARENTS PLAY: TEENAGE CHILDBEARING, PARENTAL REPUTATION, AND STRATEGIC TRANSFERS
}

\author{
Lingxin Hao \\ V. Joseph Hotz \\ Ginger Zhe Jin \\ Working Paper 7670 \\ http://www.nber.org/papers/w7670 \\ NATIONAL BUREAU OF ECONOMIC RESEARCH \\ 1050 Massachusetts Avenue \\ Cambridge, MA 02138 \\ April 2000
}

This research was funded by a grant from the National Institute for Child Health and Human Development (R01HD34293). We wish to thank Robert Pollak, David Levine and Hongbin Cai for their suggestions at the initial stages of this research and to Gary Becker, Andrew Cherlin, Wilbert van der Klaauw, Tomas Phillipson, Paul Schultz, Duncan Thomas, participants in workshops at UC-San Diego, the NBER Summer Institute, and the University of Chicago for comments on an earlier draft of the paper. Obviously, only the authors are responsible for the content of this paper. The views expressed herein are those of the authors and are not necessarily those of the National Bureau of Economic Research.

(C) 2000 by Lingxin Hao, V. Joseph Hotz, and Ginger Zhe Jin. All rights reserved. Short sections of text, not to exceed two paragraphs, may be quoted without explicit permission provided that full credit, including (C) notice, is given to the source. 
Games Daughters and Parents Play: Teenage Childbearing,

Parental Reputation, and Strategic Transfers

Lingxin Hao, V. Joseph Hotz, and Ginger Zhe Jin

NBER Working Paper No. 7670

April 2000

JEL No. J13

\section{$\underline{\text { ABSTRACT }}$}

In this paper, we examine the empirical implications of reputation formation using a gametheoretic model of intra-familial interactions. We consider parental reputation in repeated two-stage games in which daughters' decision to have a child as a teenager and the willingness of parents to continue to house and support their daughters given their decisions. Drawing on the work of Milgrom and Roberts (1982) and Kreps and Wilson (1982) on reputation in repeated games, we show that parents have, under certain conditions, the incentive to penalize teenage (and typically outof-wedlock) childbearing of older daughters, in order to get the younger daughters to avoid teenage childbearing.

The two key empirical implications of this model is that the likelihood of teenage childbearing and parental transfers to a daughter who had a teen birth will decrease with the number of the daughter's sisters at risk. We test these two implications, using data from the National Longitudinal Survey of Youth, 1979 Cohort (NLSY79), exploiting the availability of repeated observations on young women (daughters) and of observations on multiple daughters (sisters) available in this data. Controlling for daughter- and family-specific fixed effects, we find evidence of differential parental financial transfer responses to teenage childbearing by the number of the daughter's sisters and brothers at risk.

Lingxin Hao

Department of Sociology

Johns Hopkins University

Baltimore, MD 21218

hao@jhu.edu
Ginger Zhe Jin

Department of Economics

UCLA

Los Angeles, CA 90095

jin@nicco.sscnet.ucla.edu

\author{
V. Joseph Hotz \\ Department of Economics \\ UCLA \\ Los Angeles, CA 90095 \\ and NBER \\ hotz@ucla.edu
}




\section{Introduction}

Teenage childbearing has become an issue of increasing social concern in the U.S. This concern has been fueled, in large part, by the fact that such births disproportionately occurred out-of-wedlock and by evidence that suggests that early childbearing adversely affects the wellbeing of both teen mothers and her children. ${ }^{1}$ While there is considerable controversy about the causal nature of the relationship between teenage childbearing and well-being and attainment, ${ }^{2}$ there is clear evidence that teenage childbearing is perceived as undesirable by the general public and especially by parents. For example, a recent survey found that 95 percent of adults and parents strongly supported the statement that teens should "receive a strong message from society that they should abstain from sex at least until they are out of high school."3 Other recent studies also have found evidence that adults in the U.S increasingly view early childbearing unfavorably. ${ }^{4}$

Despite these negative views about teenage childbearing, its high rates and the fact that most of these births now occur out-of-wedlock suggest that parents may have trouble finding ways to translate their attitudes and concerns into actions that reduce early and out-of-wedlock births by their daughters. There are many possible reasons for this inability. One set points to changes in the social and governmental contexts confronting young women in the U.S. over the last several decades that implicitly encourage teen and out-of-wedlock childbearing. These in-

\footnotetext{
${ }^{1}$ For example, women who bear children as teenagers are subsequently less likely to complete high school, less likely to participate in the labor force, more likely to have low earnings, and less likely to marry than are women who do not have children as teenagers. As a result, adolescent mothers, and their children, are likely to spend a substantial fraction of their lifetimes in poverty (see Upchurch and McCarthy, 1990 and Card, 1981).

2 The findings of Hotz, McElroy and Sanders (1999), Hotz, Mullin, and Sanders (1997), and Mullin (1998), among others, suggest that much of the negative association between teenage childbearing and maternal and child indicators of well-being are substantially overstated.

${ }^{3}$ Annie E. Casey Foundation (1999).

${ }^{4}$ See Luker (1996) and Gordon (1997) for evidence on the increasingly negative perceptions of teenage childbearing
} 
clude the greater access to contraceptives and abortion in the U.S. ${ }^{5}$ and the pro-natalist incentives of U.S. welfare programs. ${ }^{6}$ Each of these factors may make it harder for parents to "control" the childbearing decisions of their daughters. But, it is also possible that there are inherent limitations in the ability of parents to influence the behaviors of their children, even in the absence of such contending societal and environmental forces.

In this paper we analyze the interactions between parents and their daughters with respect to the latter's teenage childbearing decisions. In particular, we examine whether daughters decide to begin their childbearing as teenagers and the ways in which parents attempt to influence, if not control, this decision through financial and other forms of support to their daughters. Economic models of interactions between parents and their children have their origins in the work of Gary Becker. In a seminal result, summarized in his "Rotten Kid Theorem" (1974, 1976, 1991)," Becker argued that "altruistic" parents can adjust their transfers to their children to induce, but not coerce, them to take actions that maximize the total income of the family, despite these children being motivated by their narrow self-interest. ${ }^{7}$ That is, the Becker "family," through its altruistic head, is able to internalize all of the potential externalities that the actions of selfish family members may have on parents (and other members) and thereby achieve pareto-efficient resource allocations. Moreover, the Rotten Kid Theorem implies that altruistic parents do not need to resort to strategic behavior-or have external ways to bind them to precommitted responses to their children's actions_-in order to achieve such allocations, since neither children nor parents

by segments of the American populace.

${ }^{5}$ See, for example, Akerloff, Yellen and Katz (1996) and Kane and Staiger (1996) for more on the role of abortion and contraceptive access and its role in "stimulating" out-of-wedlock and teen births.

${ }^{6}$ See Becker (1996) and Rosenzweig (1998). Moreover, the recently passed Personal Responsibility and Work Opportunities Reconciliation Act (PRWORA), which radically altered the U.S. welfare system, explicitly stated that one of the acts objectives was to reduce the rates of early and out-of-wedlock childbearing in the U.S.

${ }^{7}$ Becker (1991), p. 288. 
can improve upon the transfers that altruistic parents make.

However, as noted in several subsequent papers, the Rotten Kid Theorem need not always hold. ${ }^{8}$ For example, the theorem need not hold in multi-period relationships between children and parents, ${ }^{9}$ when there is asymmetric information between family members, ${ }^{10}$ and/or when parents and children each have direct preferences over certain goods chosen by the latter. A key feature of the latter type of goods—which Becker (1991) calls merit goods-is that parents and children disagree over their value. Bergstrom (1989) proves that the Rotten Kid Theorem requires that the preferences of all family members be members of the class of transferable utility functions in order for altruistic parents to rely solely on transfers to achieve efficient intrafamily allocations without precommitment. Under the assumption of normal goods, violation of the transferable utility property can result in inefficient allocations and actions by children that altruistic parents would not have them choose. ${ }^{11}$

Bergstrom's result will come as no surprise to most parents! It formalizes the notion that parents may face serious constraints on their ability to control many of the actions their children take, especially as those children reach adolescence. At the same time, it also should not be surprising that parents will try to find ways, or strategies, to influence their daughter's actions when faced with these limitations on the influence and control they have over their children, especially over actions that are as irreversible as a daughter having a birth as a teen.

In what follows, we examine the extent to which altruistic parents, from their point of view, are able to reduce, although not eliminate, any inefficiencies with respect to the daughter's

\footnotetext{
${ }^{8}$ See Lindbeck and Weibull (1988), Bruce and Waldman (1990) and Bergstrom (1989).

${ }^{9}$ See Hirshleifer (1977, 1985), Lindbeck and Weibull (1988), and Bruce and Waldman (1990) for discussions of the sorts of inefficiencies that arise when parents and their children engage in repeated interactions.

${ }^{10}$ See Bergstrom (1989).

${ }^{11}$ See also the discussion of this point in the Foreword to the enlarged edition of Becker's Treatise on the Family.
} 
teenage childbearing decisions without explicitly relying on the assumption of transferable utility or an exogenously-given means of precommitment. We consider a model in which altruistic parents (or parent) and their selfish teenage daughters play a two-stage game in which daughters decide whether to have an early birth and parents decide whether to respond by withholding resources to them. As implied by Bergstrom (1989), this game does not, in general, result in efficient decisions, at least not when there is "conflict" between daughters and parents over this "action," i.e., the transferable utility condition does not hold. However, parents have an incentive to try to establish a reputation for being willing to "punish" older daughters who have teen births in order to deter their younger ones from doing the same. We adapt the non-cooperative, gametheoretic reputation models of Milgrom and Roberts (1982) and Kreps and Wilson (1982) to the family context. In what follows we adapt a key feature of the Kreps-Wilson and MilgromRoberts models by assuming that older daughters are uncertain about their parents' true preferences over their having births as teenagers. ${ }^{12}$

As we show below, the application of this reputation model of parent-daughter interactions has at least two potentially testable implications for the teenage childbearing decisions of daughters and the resources transfers that parents make to them. If parents use their transfers to establish a reputation for punishing teen births, the likelihood of teenage childbearing and parental transfers to daughters who have teen births will both decrease as the number of younger sisters "at risk" for such a birth declines. We examine the empirical validity of these two implications, using data on the timing of daughters' first births and the incidence of two alternative

\footnotetext{
${ }^{12}$ We note that recent "collective" models of family decision-making, such as the one in Browning and Chiappori (1998), maintain the assumption that members of a family, through "repeated" interactions, come to learn the preferences of other family members. In our context, the unique and infrequent nature of childbearing actions of daughters makes it less obvious that oldest daughters, will know their parents' true preferences about their having births as teens. In the end, the validity of this assumption, through its testable implications about observed behavior, is an empirical matter.
} 
forms of parental transfers.

The remainder of the paper is organized as follows. In Section 2 we characterize the repeated two-stage game of parents and their daughters. We discuss the potential solutions when daughters know their parents' preferences over teenage childbearing and the scope for establishing parental reputation when daughters are uncertain about these preferences. In Section 3, we outline a set of "reduced form" empirical implications of our game-theoretic model. Section 4 outlines the econometric issues that can compromise the testing of these implications, including the endogeneity of the teenage childbearing choices of daughters in the econometric specifications of parental transfer decisions. We exploit the availability of longitudinal data on the transfers parents make to their daughters and the availability of multiple daughters (sisters) for a given family in order to implement daughter- and family-specific fixed-effects estimators in our analysis. Section 5 provides a more detailed discussion of the data we analyze, namely that from the National Longitudinal Survey of Youth, 1979 Cohort (NLSY79).

In Section 6, we present our empirical estimates. We find evidence that daughters with a larger number of sisters under age 18 , who had a teen birth, are more likely to have support from parents withheld than is the case for daughters who have no or fewer sisters under age 18. Such findings are consistent with the view that parents are acting strategically to establish reputations with respect to their responses to teenage childbearing by older daughters in order to reduce teenage births to younger daughters. In the final section of the paper, we offer some concluding remarks.

\section{Game-Theoretic Models of Parent and Daughter Decision-Making}

In this section we consider the interactions between parents and a daughter with respect to the latter's decision about teenage childbearing and parents' decision about transfers. We treat 
parents — be they a mother-father pair or a single parent — as one decision-maker and assume that parents are altruistic with respect to their daughters. In contrast, daughters are assumed to be selfish, caring only about their own well-being. Parents and daughters care about their own consumption levels and each have preferences over whether the daughter has a child (a grandchild to the parents) as a teenager. As noted above, children borne by women who are teenagers typically are born out-of-wedlock. Parents and daughters may not have the same "feelings" toward such births. Parents, and each of their daughters, are assumed to play a two-stage game. In the first stage, a daughter takes an action, $b$, which is giving, or not giving, birth as a teenager. After observing the daughter's $b$ decision, the parents decide whether to provide their daughter with resources, or transfers, $t$.

More precisely, a daughter, denoted by $d$, cares only about her own consumption, $c_{d}$, and a child borne as a teenager, $b$. Let the daughter's utility be denoted by

$$
U_{d} \equiv U_{d}\left(c_{d}, b\right)
$$

To account for their own consumption and altruism toward their children, parents are assumed to have the following two personalities. The first personality is "consumer-parents," who derive utility from their own consumption and whether they have grandchildren who were born to their teenage daughters. The consumer-parents care about their own consumption, $c_{p}$, and the action, $b$, taken by their daughters, with their utility given by

$$
U_{p} \equiv U_{p}\left(c_{p}, b\right)
$$

The second personality of parents is as an altruist, acting as a social planner for the family. This is the "planner-parents," which has a welfare function given by

$$
W_{p}\left[U_{p}\left(c_{p}, b\right), U_{d}\left(c_{d}, b\right)\right] .
$$

As the planner-parents' welfare function makes clear, teenage births $(b)$ represent a public good 
or in Becker's terminology, a merit good. Parents have an exogenously given income, $I_{p}$, to support their own consumption and that of their daughter, via transfers. Thus, the parent's budget constraint is given by

$$
I_{p}=c_{p}+t
$$

For now, we assume that the daughter has no income of her own; in the empirical analysis we do allow for such income and we assume that the daughter is totally dependent on transfers from the parents to support her consumption, $c_{d \cdot}{ }^{13}$ That is, the daughter's budget constraint is given by

$$
c_{d}=t .
$$

The two-stage game that parents and each daughter play can be described as follows:

Stage 1: In daughter's decision about teenage childbearing, her problem is to

$$
\max _{b} U_{d}(t(b), b),
$$

where $t=t(b)$ is the parent's best response function from Stage 2 .

Stage 2: In planner-parents' decision about transfers, their problem is to

$$
\max _{t} W_{p}\left[U_{p}\left(I_{p}-t, b\right), U_{d}(t, b)\right],
$$

where $b$ is taken as given, $W_{p 1} \equiv \frac{\partial W_{p}}{\partial U_{p}}>0$ and $W_{p 2} \equiv \frac{\partial W_{p}}{\partial U_{d}}>0$.

Finally, we assume, from the planner-parents' standpoint, that both the consumer-parents' and daughter's utility are normal goods and that $W_{p}$ has nice concavity to guarantee a unique solution to this game.

To fix ideas and examine alternative solutions to this parent-daughter game, we assume that the preferences of the players are restricted as follows. First, we assume that all planner-

\footnotetext{
${ }^{13}$ For now, we assume that there is no consumption on the part of grandchildren. Below, we consider the implications of allowing the actions of daughters to entail a "cost" to their, and possibly their parents', consumption.
} 
parents disapprove of teenage childbearing, regardless of whether they make transfers or not. Thus,

$$
\text { All Parents: } W_{p}(t=\cdot, b=0)>W_{p}(t=\cdot, b=1)
$$

for all $t$, where $W_{p}\left(t=v_{1}, b=v_{2}\right) \equiv W_{p}\left[U_{p}\left(I_{p}-v_{1}, v_{2}\right), U_{d}\left(v_{1}, v_{2}\right)\right]$ and where we let $b \in\{1,0\}$, where $b=1$ denotes that a daughter had a teen birth and $b=0$ that she did not, and $t \in\{1,0\}$, where $t=1$ denotes the parents making a transfer to their daughter and $t=0$ that they do not.

With respect to the degree of parental altruism, we assume that there two types of parents. One type, "forgiving" parents, have strong altruistic feelings toward their daughters, relative to their dislike of teen childbearing. Such parents will not, ex post, withhold transfers if their daughter has a teen birth, even though they do not like this behavior. That is, the forgiving parents' preferences satisfy the following ordering:

$$
\text { Forgiving Parents: } W_{p}(t=1, b=1)>W_{p}(t=0, b=1) \text {. }
$$

Alternatively, some parents, the "unforgiving" ones, are less altruistic. Such planner-parents are not willing to forgive their daughter's transgressions and would prefer to punish daughters who have teen births. In this case,

$$
\text { Unforgiving Parents: } W_{p}(t=1, b=1)<W_{p}(t=0, b=1) \text {. }
$$

With respect to the preference orderings of daughters over teenage childbearing $(b)$ and own consumption $\left(c_{d}\right)$, we assume that daughters prefer parental transfers and teen births to no transfers and no teen births. More completely, we assume the following structure on each daughter's preferences,

Daughters: $U_{d}(t=1 ; b=1)>U_{d}(t=1 ; b=0)>U_{d}(t=0 ; b=1)>U_{d}(t=0 ; b=0)$,

where the particular ordering over the middle two bundles is less crucial than the ordering of the outer two. 
We next characterize alternative solutions to this game depending on whether or not daughters know their parents' preferences.

\subsection{Parent-Daughter Games under Perfect and Complete Information}

As a first case, we assume that both players in the game, i.e., the daughter and the parents, have perfect and complete information about each other's preferences. For now, we assume that the game is played once between the parents and each of their daughters. We define efficient allocations for parents and their daughter as those that the planner-parents would make if they chose both $b$ and $t$ to maximize $W_{p}$. As noted in the Introduction, if the utility functions of all players, $U_{p}$ and $U_{d}$, are conditionally transferable, the planner-parents always can devise a transfer such that daughter takes into account the full consequences that having a teen birth has on her consumer-parents. That is, Becker's Rotten Kid Theorem holds if and only if the preference orderings of parents and their daughters are transferable. ${ }^{14}$ Without this assumption, the allocations achieved in the above game between daughters and their parents need not be efficient. This is because the daughter may not take account of all the "externalities" that her teenage childbearing choice imposes on her parents. As a result, the daughter will tend to over- or under-consume teenage childbearing, depending on the functional forms of $U_{p}$ and $U_{d}$, in the above game.

Consider, for example, the decision-trees for the daughter-parent game given in Figure $1,{ }^{15}$ where we assign numerical values to the various payoffs for forgiving and unforgiving parents, respectively. As noted above, the daughter moves first, deciding whether to have a teen birth. If she does not (the "No Teen Birth" action), we assume that her parents will respond by providing her with a transfer. If she does (the "Teen Birth" action), her parents have a choice as

\footnotetext{
${ }^{14}$ Bergstrom (1989) proves that transferable utility is a necessary and sufficient condition for the Rotten Kid Theorem to hold.

${ }^{15}$ Each daughter participates only once in the game, according to birth order.
} 
to how to respond. Depending on their preferences, parents will either provide a transfer and acquiesce to the daughter's action by not punishing her ("Parents Acquiesce") or they will withhold their support and punish her ("Parents Punish"). ${ }^{16}$ Given the assigned payoffs, the socially optimal action is for the daughter not to have a child as a teen, i.e., $b=0$, for either type of parents. With no teen birth, the planner-parents reach their highest utility $\left(W_{p}=1\right)$, but the daughter obtains a utility level $\left(U_{d}=1\right)$ that is less than she would be able to get in case of "Teen Birth, Parents Acquiesce" $\left(U_{d}=2\right)$.

The actual solution will vary, depending on the parents' type of preferences. If the parents of the forgiving type, they get $W_{p}(t=1, b=1)=0.5$ by acquiescing and $W_{p}(t=0, b=1)=-1$ by punishing their daughter if she has a teen birth. In this case, the forgiving parents are better off acquiescing. Knowing that the forgiving parents always acquiesce to a teen birth, the daughter obtains $U_{d}=2$ by "Teen Birth" and $U_{d}=1$ by "No Teen Birth." Therefore, the best choice for daughter is a "Teen Birth." Thus, the unique sub-game perfect Nash equilibrium is "Teen Birth, Parents Acquiesce." ${ }^{17}$ In equilibrium, their daughters manipulate forgiving parents to accept a sub-optimal action. In this case, the equilibrium allocation does not correspond to the social optimum. If, in contrast, the parents are unforgiving, $\left[W_{p}(t=0, b=1)=-1>W_{p}(t=1, b=1)=-2\right]$ and daughters, knowing this about their preferences and, thus, how parents will react to a teen birth, will choose not to have such a birth, i.e., $\left[U_{d}(t=0, b=1)=-1<U_{d}(t=1, b=0)=1\right]$. Thus, the only Nash equilibrium is the "No Teen Birth, Parents Punish" one in which case the equilibrium is socially optimal.

\footnotetext{
${ }^{16}$ Since the younger daughters observe the exact payoffs $\left(W_{p}\right)$ of the parent in earlier periods of the game, the "forgiving" parents must hold the same level of payoffs as the "unforgiving" parents if they decide to punish older daughters' teen births. Otherwise, the payoffs reveal the parents' type immediately.

${ }^{17}$ The "No Teen Birth, Parent Punishes" outcome is also a Nash equilibrium, but is not credible and violates the rationality of sub-game backward induction.
} 


\subsection{Parents Establishing a Reputation: A Finitely Repeated Game with One-Sided Uncertainty about Preferences}

We now turn to the case where daughters do not know their parents' preferences with certainty. This uncertainty about preferences gives rise to the potential for parents to make strategic use of their transfers to daughters in an attempt to obtain greater "conformity" of their daughters' actions with their own preferences over teenage childbearing. That is, we examine the possibility that altruistic parents treat their daughters differently by birth order in order to establish a credible "reputation" for punishing teen childbearing. ${ }^{18}$ Our analysis is an application of the repeated-games, reputation model developed by Milgrom and Roberts (1982) and Kreps and Wilson (1982). These authors consider the problem of a monopolist, the "incumbent firm," that prefers to avoid rival firms entering their industry in order to maintain their monopoly rents. In their model, fighting off such entry attempts, by setting prices at levels below costs, will result in temporary losses to the incumbent firm. But, by establishing a credible reputation of fighting entry, such temporary losses may be compensated by the gains from forestalling future entrants without having to resort to price cutting actions. A key assumption of their model is that potential entrants are uncertain about the exact nature of the incumbent firm's payoff functions, i.e., its cost structure.

Adapting the Milgrom-Roberts and Kreps-Wilson asymmetric information assumptions to the family context, ${ }^{19}$ parents are assumed to have complete information about the preferences of all of their daughters. In contrast, daughters, at least those in the early rounds (i.e., older

\footnotetext{
${ }^{18}$ Note that the model outlined below can also accommodate the case where parents would prefer their daughters to bear children earlier than the daughters prefer. Such a case may be relevant to those parents who lament their fact that their daughters have not provided them with grandchildren!

${ }^{19}$ The informational structure of the game can take several forms. In the Milgrom-Roberts extended model, there is a continuum of parent types and daughters do not ever know the parent's payoffs. In contrast, in the Kreps-Wilson two-type two-player two-action model, the parent's payoff history is observable to all daughters, Despite different model structures, both specifications yield similar conclusions with respect to reputation effects. As noted in the
} 
daughters), are assumed not to know whether their parents are forgiving or unforgiving types with perfect certainty. The oldest daughters may have some initial, or prior, beliefs about the parents' type, which may be formed from previous interactions with her parents as she (and her sisters) grow up, from her knowledge of her parents' background, or from observing the responses to teenage childbearing of other families in her family's neighborhood or social class. ${ }^{20}$ But, we assume that the priors that the oldest daughter forms about her parents' preference orderings over teenage childbearing are not degenerate. That is, we assume that it is impossible for the oldest daughter (and maybe some or all of her remaining sisters) to discern exactly how her parents will feel about and react to her having a teen birth solely from past interactions with her parents and from the interactions of other families. Finally, we do assume that younger daughters can observe the childbearing outcomes and the parental transfer responses for all of their older sisters. Thus, we do not rule out the possibility that younger daughters, who play in later rounds of this family game, can acquire information about parental preferences toward teen childbearing.

More precisely, assume that there are $N$ daughters in a family in which each daughter's teenage childbearing decision represents one round of a repeated game played with parents. ${ }^{21}$ The order of the rounds is from the oldest $(N)$ to the youngest (1) daughter. The planner-parents maximize the (discounted) sum of the welfare associated with each round. For now, we assume that parents do not discount the utility of future relative to current rounds of the game. Below, we

text, we follow the specification used in the Kreps-Wilson version of the model.

${ }^{20}$ See Nechyba (1999) for a model of social approval of illegitimate childbearing and its potential role in explaining the causal relationship between out-of-wedlock childbearing and the pro-natalist incentives of the AFDC system.

${ }^{21}$ For simplicity, we ignore the possibility that each daughter may engage in teenage childbearing more than once. More generally speaking, if the reputation theory applies to a class of bad behavior, round of game does not depend on children's birth order, but also rely on all types of child behaviors that parents would like to influence via reputation. 
discuss the robustness of our findings to discounting.

The case of interest is whether forgiving parents, who knows that their daughters are uncertain about their actual type, will have an incentive to mimic the unforgiving type so as to establish a reputation for "being tough." Most of the discussion that follows is based on this particular case. But, before turning to that case, consider the situation facing families with only one daughter, i.e., $N=1$. In this situation, even if the daughter is uncertain about the parent-type, it is optimal for parents to follow the static equilibrium strategy and there is no role for establishing a reputation. That is, forgiving parents always will acquiesce if their only daughter has a teen birth while unforgiving parents always punish such an action. Given her prior belief that her parents are forgiving types, an only daughter will choose $b$ to maximize her expected payoffs. She will have a birth as a teen only if she is confident enough about the likelihood of having forgiving parents, i.e. that the daughter's prior beliefs that her parents are the forgiving type exceeds some threshold.

We now turn to the case of $N$-daughter families, where $N>1$. A daughter is labeled as the $k^{\text {th }}$ daughter if she has $k$-1 younger sisters. (So the oldest daughter is daughter $N$ and the youngest is daughter 1.) Let $\pi_{k}$ denote the daughter $k$ 's belief, or probability, of having forgiving parents before she chooses her action, $b$. Thus, the prior belief of the oldest daughter is $\pi_{N}$ and, as the game moves on, this belief is updated to $\pi_{N-1}, \pi_{N-2}, \ldots, \pi_{1}$. Define a sequence of belief thresholds $\left\{\bar{\pi}_{k}\right\}$, where

$$
\bar{\pi}_{1}=\frac{U_{d}(t=1, b=0)-U_{d}(t=0, b=1)}{U_{d}(t=1, b=1)-U_{d}(t=0, b=1)}
$$

and

$$
\bar{\pi}_{k}=1-\left(1-\bar{\pi}_{1}\right)^{k}
$$


The numerator in (12) represents the maximum cost of teenage childbearing while the denominator denotes the benefits of giving a birth as a teenager and obtaining parental support. Therefore, $\bar{\pi}_{1}$ represents the "cost-benefit" ratio that makes a daughter indifferent between having or not having a teen birth. If the daughter believes her parents' preferences are more lenient than $\bar{\pi}_{1}$, the "benefits" of having a birth overweigh the "costs" and she chooses to have a teen birth. As one moves up the birth order, from the youngest to the oldest, it follows that there is more reputation gain for the forgiving parents to punish teenage childbearing. As a result, older daughters must have strong beliefs that their parents are forgiving types in order to choose to have a teen birth, which implies that $\bar{\pi}_{k}$ increases with $k$.

Following Kreps and Wilson (1982) and assuming that parents are sufficiently patient, the sequential equilibrium for the $N$-daughter family can be described in three regimes. Suppose the prior of the oldest daughter, $\pi_{N}$, falls between $\bar{\pi}_{k^{*}}$ and $\bar{\pi}_{k^{*}+1}$. Define Regime 1 as all daughters who are older than daughter $k^{*}$, i.e., $k>k^{*}$. Parents, with probability one, will punish all the $k^{\text {th }}$ daughters, $k>k^{*}$, that have a teen birth. Because all daughters in the family know this punishment policy, the $k^{\text {th }}$ daughter $\left(k>k^{*}\right)$ will try to avoid having a teen birth. Furthermore, because parents always punish during Regime 1, the daughters' prior about their parents' type remains equal to $\pi_{N}$ until $k=k^{*}$. After $k^{*}$, parents adopt a randomized strategy for determining what their transfer outcome, i.e., punishment strategy, will be. In particular, parents choose to punish the $k^{\text {th }}$ daughter $\left(k>k^{*}\right)$ with probability,

$$
p_{k}=\frac{1-\pi_{k}}{\pi_{k}} \cdot \frac{\bar{\pi}_{k-1}}{1-\bar{\pi}_{k-1}} .
$$

Let $n *$ represent the first round (daughter) in which parents acquiesce to teen childbearing by that daughter, where $k^{*}>n^{*}$. On the $n^{*^{\text {th }}}$ daughter, the parents reveal their type to be "forgiv- 
ing." Define the interval $k^{*}>k \geq n^{*}$ as Regime 2 and $k<n^{*}$ as Regime 3. In Regime 2, although parents employ a randomized punishment strategy, although the actual observed parental transfers in this regime are all $t=1$. Mimicking the parents' randomized transfer strategy, daughters in Regime 2 follow a randomized strategy with respect to having births as teens. In particular, the $k^{\text {th }}$ daughter $\left(k^{*}>k \geq n^{*}\right)$ will no longer try to avoid a teen birth with probability one. Rather she will try to avoid it with probability greater than or equal to $\rho_{k}=1-\bar{\pi}_{k}$. Finally in Regime 3 , the parent's type is no longer uncertain and the equilibrium reduces to the static game equilibrium, i.e., the "Teen Birth, Parents Acquiesce" outcome, for the $k^{\text {th }}$ daughters, where $k<n$ *

Figure 2 displays the three-regime solution to the daughters-parent, repeated game with reputation effects. Strictly speaking, the model implies that the transfer and birth outcomes in Regimes 1 and 3 are deterministic. In Regime 1, parents will punish all teen births and, as a result, daughters in this regime would never choose to have a teen birth. In Regime 3, no teen births will be penalized so the theory implies that all younger daughters will choose to have one with certainty. It is more realistic to assume that teen births in these two regimes are stochastic, conditional on the intentions and birth control actions taken by a daughter. In contrast, the daughter's and the parents' strategies in Regime 2 depend on the previous daughter's childbearing outcome and the parents' transfer response to that outcome. That is, there is a truly sequential nature to choices that parents and daughters make in the second regime and to the actual round of the game (the particular daughter) at which the family moves from Regime 2 to Regime 3.

There are several caveats and extensions to the reputation model as applied to the family context. The first concerns the role of discounting of the future by parents. In the above model we assumed that parents did not discount the impacts of future rounds of the game, i.e., we implicitly assumed that their discount factor, $\delta_{p}$, was equal to 1 . In fact, the three-regime equilib- 
rium described above only holds when $\delta_{p}$ equals or is sufficiently close to 1 . Kreps and Wilson (1982) show that as this discount factor becomes sufficiently small, only Regime 3 exists in the equilibrium. In this case, forgiving parents have much less of an incentive to establish a reputation for punishing the teenage childbearing of any of their daughters, since the discounted benefits of obtaining greater conformity by their younger daughters in the future is likely to be exceeded by the costs of punishing their older daughters. In the empirical analysis presented below, we propose a way of detecting the impacts of such discounting of future payoffs by parents.

Second, the general implications of reputation theory outlined above can be extended to other juvenile or undesirable behavior and the corresponding parental responses. If, for example, parents have common views, or preferences, over a class of behaviors, then parental responses to one behavior will be informative signals about other behaviors. For example, although we focus on teenage childbearing is this paper, punishing daughters' childbearing may signal parent's general attitudes toward other undesirable behaviors, such as dropping out of school, crimes, illegal drug use, alcohol and smoking addictions.

Finally, the simple reputation model outlined above focused on the impact of parental reputation effects on daughters. Parents also might be concerned the decisions that their sons make about fathering children as teens or other behaviors they want them to avoid. As such, parents, in their responses to the childbearing decisions of their older daughters, may seek to establish reputations to influence their younger sons as well as their younger daughters. ${ }^{22}$ Thus, we might expect parental transfer responses to teen childbearing to depend on both the number of younger daughters and the number of younger sons. We investigate this possibility in the empirical work below.

\footnotetext{
${ }^{22}$ We note that the literature on the effects of teenage childbearing has devoted much less attention to the consequences for fathers. One exception is the work by Brien and Willis (1997).
} 


\section{Testable Implications of Reputation Models on Teenage Childbearing and Parental Transfers}

The reputation game between parents and their daughters implies several potentially testable implications with respect to the teenage childbearing of daughters and the parents' transfer behavior conditional on a daughter's birth choice. We now characterize these decisions rules and discuss these testable implications.

Let $b_{n p a_{n}^{\prime}}$ denote the $0 / 1$ indicator for whether the $n^{\text {th }}$ daughter in the $p^{\text {th }}$ family has a teen birth when the parents are age ${a_{n}^{\prime 23}}^{23}$ and $t_{n p \tau}$ denote the $0 / 1$ indicator for whether the $p^{\text {th }}$ parents provide a transfer to the daughter at parents' age $\tau$. (In the empirical analysis presented below, we classify births occurring before a daughter is age 18 as a teen birth and consider transfers to the daughter when she is age 18 and older.) Let $G_{b}(\cdot)$ denote the index function for this daughter's teenage childbearing decision, $G_{b}(\cdot) \geq 0$ implies $b_{n p a_{n}^{\prime}}=1$. The reputation model implies that $G_{b}(\cdot)$ can be represented as follows in its most general form

$$
G_{b}\left(n_{p a_{n}^{\prime}}, k_{p}^{*}, \pi_{n p}, I_{p a_{n}^{\prime}},\left\{E_{a_{n}^{\prime}} I_{p i}\right\}_{i=a_{n}^{\prime}+1}^{A_{p}}, I_{n p a_{n}^{\prime}},\left\{E_{a_{n}^{\prime}} I_{n p i}\right\}_{i=a_{n}^{\prime}+1}^{A_{n}} \mid \Omega_{n p a_{n}^{\prime}}\right)
$$

where $n_{p a_{n}^{\prime}}, k_{p}^{*}$, and $\pi_{n p}$ are defined in the previous section; $I_{p a_{n}^{\prime}}$ is the parents' income at $a_{n}^{\prime}$; $\left\{E_{a_{n}^{\prime}}^{\prime} I_{p i}\right\}_{i=a_{n}^{\prime}+1}^{A_{p}}$ is the expected future income stream of the parents, where the expectation is taken at $a_{n}^{\prime}$ and is conditioned on the $n^{\text {th }}$ daughter's information as of $a_{n}^{\prime}$ and where $A_{p}$ is the parents' age of death; $I_{n p a_{n}^{\prime}}$ is the $n^{\text {th }}$ daughter's income at $a_{n}^{\prime} ;\left\{E_{a_{n}^{\prime}} I_{n p i}\right\}_{i=a_{n}^{\prime}+1}^{A_{n}}$ her expected future income stream, where $A_{n}$ is the age of the $n^{\text {th }}$ daughter's death (measured in terms of parental age); and $\Omega_{n p a_{n}^{\prime}}$ denotes the $n^{\text {th }}$ daughter's information set as of $a_{n}^{\prime}$, which contains past realizations of $b_{j p \tau}$,

\footnotetext{
${ }^{23}$ Throughout this section, we index the ages of daughters in terms of parental age.
} 
$t_{j p \tau}, I_{p \tau}$ and $I_{j \tau}$ for $j=n+1, \ldots, N$ and $\tau=0, \ldots, a_{n}^{\prime}$, the parents' rate of time preference, $\delta_{p}$, and tastes parameters, $\omega_{j p}$, for daughters $j=n, \ldots, N$. With respect to transfer decisions, let $G_{t}(\cdot)$ denote the index function for this daughter's teenage childbearing decision, $G_{t}(\cdot) \geq 0$ implies $t_{n p \tau}=1$. It follows from the theory that $G_{t}(\cdot)$ can be represented as

$$
G_{t}\left(b_{n p \tau}, n_{p \tau}, k_{p}^{*}, \pi_{n p}, N_{p}, I_{p \tau},\left\{E_{\tau} I_{p i}\right\}_{i=\tau+1}^{A_{p}}, I_{n p \tau},\left\{E_{\tau} I_{n p i}\right\}_{i=\tau+1}^{A_{n}} \mid \Omega_{p \tau}\right),
$$

where $N_{p}$ is the total number of daughters (or sons and daughters) and $\Omega_{p \tau}$, the $p^{\text {th }}$ parents' information set as of $\tau$ contains $\Omega_{n p \tau}$ plus the taste parameters, $\omega_{j p}$, for the remaining daughters, $j=$ $1, \ldots, n$, and the parents' taste parameter, $\phi_{p}$.

There are a number of predictions with respect to how parental transfers and the $n^{\text {th }}$ daughter's teenage childbearing decisions vary with the birth order of the daughter, the past parental choices and the choices of older daughters as well as the parental response to the $n^{\text {th }}$ daughter's teenage childbearing choice. Unfortunately, the data used in this study-the NLSY79-does not contain sufficient information on the past choices made within each family to allow us to test the full range of these predictions. Therefore, we test a more limited, or "reduced form," set of predictions from the reputation model in this paper. To derive such predictions, we need to express the decision rules in (15) and (16) in terms of family-specific initial conditions and exogenous time-varying characteristics and eliminate their dependence on the teenage childbearing choices of older daughters and the past transfer choices of parents. To accomplish this, note that past choices by parents and daughters enter the decision rules in (15) and (16) through the updated beliefs about the preferences of parents, i.e., through $\pi_{n p}$. In particular, the reputation model implies that $\pi_{n}$ can be represented as follows: 


$$
\pi_{n p}=\tilde{\pi}\left(\pi_{N p}, N_{p},\left\{b_{i p}\right\}_{i=n+1}^{N},\left\{\left\{t_{j p i}\right\}_{i=a_{j}^{\prime}}^{a_{n}^{\prime}}\right\}_{j=n+1}^{N},\left\{I_{p i}\right\}_{i=0}^{a_{n}^{\prime}},\left\{\left\{I_{j p i}\right\}_{i=a_{j}^{\prime}}^{a_{n}^{\prime}}\right\}_{j=n+1}^{N} \mid \omega_{N p}, \ldots, \omega_{1 p}, \delta_{p}\right) \cdot{ }^{24}
$$

Using (15) and (16) to recursively substitute for past values of $b_{n p a_{n}^{\prime}}$ and $t_{n p \tau}$, it follows that $\pi_{n p}$ can be expressed as a function of lagged parental income, daughter's income and the tastes the parents and the daughters, i.e.,

$$
\pi_{n p}=\pi\left(\pi_{N p}, N_{p},\left\{I_{p i}\right\}_{i=0}^{a_{n}^{\prime}},\left\{\left\{I_{j p i}\right\}_{i=a_{j}^{\prime}}^{a_{n}^{\prime}}\right\}_{j=n+1}^{N} \mid \omega_{N p}, \ldots, \omega_{n p}, \delta_{p}\right) .
$$

Substituting the expression in (18) for $\pi_{n p}$ in both (15) and (16), $G_{b}$ and $G_{t}$ can be rewritten as:

$$
\begin{gathered}
G_{b}\left(n_{p a_{n}^{\prime}}, k_{p}^{*}, \pi_{N p}, N_{p},\left\{I_{p i}\right\}_{i=0}^{a_{n}^{\prime}},\left\{E_{a_{n}^{\prime}} I_{p \tau}\right\}_{\tau=a_{n}^{\prime}+1}^{A},\left\{\left\{I_{j p i}\right\}_{i=a_{j}^{\prime}}^{a_{n}^{\prime}}\right\}_{j=n+1}^{N},\left\{E_{a_{n}^{\prime}} I_{n p \tau}\right\}_{\tau=a_{n}^{\prime}+1}^{A^{*}} \mid \omega_{N p}, \ldots, \omega_{n p}, \delta_{p}\right) \\
G_{t}\left(b_{n p \tau}, n_{p \tau}, k_{p}^{*}, \pi_{N p}, N_{p},\left\{I_{p i}\right\}_{i=0}^{\tau},\left\{E_{\tau} I_{p i}\right\}_{i=\tau+1}^{A}\left\{\left\{I_{j p i}\right\}_{i=a_{j}^{\prime}}^{\tau}\right\}_{j=n+1}^{N},\left\{E_{\tau} I_{n p i}\right\}_{i=\tau+1}^{A^{*}} \mid \omega_{N p}, \ldots, \omega_{1 p}, \phi_{p}, \delta_{p}\right) .
\end{gathered}
$$

The reputation model's most robust, and testable, predictions concern how parents' and daughters' decisions vary with the birth order of the parents' children. Consider the parents' decision to make transfers to a daughter, conditional on her teenage childbearing choice. Under the conditions described in Section 2.2, the game-theoretic model implies that parents have an incentive, regardless of their type, to establish a reputation for being unforgiving by treating the behavior of older daughters differently than their younger sisters are treated. If so, the incidence and amounts of parental transfers to daughters who have teen births should be lower for older daughters, relative to younger ones, all other things being equal. That is,

$$
\frac{\partial\left[\partial G_{t}\left(b_{n p a_{n}^{\prime}}, n_{p a^{\prime}}, k_{p}^{*}, \pi_{N p}, \ldots \mid \omega_{N p}, \ldots, \omega_{1 p}, \phi_{p}, \delta_{p}\right) / \partial b_{n p a_{n}^{\prime}}\right]}{\partial n_{p a_{n}^{\prime}}}<0 .
$$

As noted in Section 2.2, establishing such a reputation for being unforgiving will not be optimal (or credible) if either (a) the preferences of parents and their daughters are transferable or (b)

\footnotetext{
${ }^{24}$ Note that the $\pi$ s are assumed to be a function of the tastes of all of the daughters (or children) in the family.
} 
daughters are not uncertain about the parents' preference type, in which case the effect of the number of remaining children on $t_{n p \tau}$ should be zero.

The reputational incentives of the model also imply birth order effects with respect to the teenage childbearing decisions of daughters. Older daughters, uncertain as to their parents' type, will try to avoid having teenage births but this incentive to avoid teen births will be lower for younger daughters in the family. Alternatively stated, the model implies that

$$
\frac{\partial G_{b}\left(n_{p a_{n}^{\prime}}, k_{p}^{*}, \pi_{N p}, N_{p}, \ldots \mid \omega_{N p}, \ldots, \omega_{n p}\right)}{\partial n_{p a_{n}^{\prime}}}<0 .
$$

As with parental transfer decisions, if either condition (a) or (b) noted above apply, parents have no incentive to establish reputations for being unforgiving and, thus, $b_{n p a_{n}^{\prime}}$ should not vary with $n_{p a_{n}^{\prime}}$, all else equal. Note that the reputation effects described in (21) and (22) are established holding past, current and expected future parental and daughters' incomes constant. Failure to do so would confound any reputation effect of the number of younger daughters remaining at risk to have a teen birth with the effects of life cycle changes in parental income. In particular, to the extent that the income of parents rise as they get older, younger daughters with teen births could receive greater transfers simply because their parents are wealthier for these daughters than they were when their older daughters were making decisions about teen births. In the next section, we discuss how we deal with life cycle changes in parental wealth and the potential for dealing with its potentially confounding influence when estimating reputation effects.

The model also implies that the parents' incentive to establish a reputation for punishing teen births - and, thus, the effect of birth order on the teenage childbearing decisions of their daughters-will vary with parents' rate of time preference. In particular, the more impatient are parents, the less likely they are to respond by withholding transfers after a teen birth and, as such, 
the less likely daughters are to avoid teen births as a function of the number of younger sisters they have. That is,

$$
\begin{gathered}
\frac{\partial\left[\partial^{2} G_{t}\left(b_{n p a_{n}^{\prime}}, n_{p \tau}, k_{p}^{*}, \pi_{N p}, \ldots \mid \omega_{N p}, \ldots, \omega_{1 p}, \phi_{p}, \delta_{p}\right) / \partial b_{n p a_{n}^{\prime}} \partial n_{p \tau}\right]}{\partial \delta_{p}}<0, \\
\frac{\partial\left[\partial G_{b}\left(n_{p}, k_{p}^{*}, \pi_{N p}, N_{p}, \ldots \mid \omega_{N p}, \ldots, \omega_{n p}\right) / \partial n_{n p}\right]}{\partial \delta_{p}}<0 .
\end{gathered}
$$

We consider the predictions in (24) and (23) to be more tenuous than (22) and (21), since the nature of the equilibrium in reputation games is less clear cut as $\delta_{p}$ deviates from 1 . Moreover, testing this implication is compromised by the lack of direct measures of parental rates of time preference. Nonetheless, we examine these latter two predictions in the empirical analysis presented below by examining how birth order effects on teenage childbearing and parental transfer responses vary with the gap in ages between a daughter and her next oldest sister (or brother).

\section{Econometric Specification Issues}

To test the validity of the above implications of the reputation model of parent-daughter interactions, we need to formulate estimable versions of (19) and (20). To proceed, we need to be more explicit about the nature of the processes generating the income of parents and daughters over their respective life cycles. This is necessary for two reasons. First, the data we use does not contain complete histories of parental income (or, in some cases, of the incomes of all daughters). Thus, we cannot condition directly on these variables in (19) or (20). Second, we need to account for the forecasting of the future levels of incomes of parents and daughters in (19) and (20). To address both, we make several simplifying assumptions about the nature of the processes generating $I_{p \tau}$ and $I_{n p \tau}$, respectively. We continue to assume that both sources of income are exogenously given vis-à-vis birth and transfer decisions. Furthermore, we assume that they can 
be represented as follows:

$$
\begin{gathered}
I_{p \tau}=h\left(\tau_{p}, \boldsymbol{x}_{p}\right)+\psi_{p}+\varepsilon_{p \tau}, \\
I_{n p \tau}=h\left(\tau_{n p}, \boldsymbol{x}_{n p}\right)+\kappa_{n p}+v_{n p \tau},
\end{gathered}
$$

respectively, where $h(\cdot)$ is a function of age, $\tau_{i}$, a vector of person-specific observable characteristics, $\boldsymbol{x}_{i}, i=p, n p$, and a permanent-transitory stochastic structure, where $\psi_{p}$ and $\kappa_{n p}$ are the permanent components and $\varepsilon_{p \tau}$ and $v_{n p \tau}$ are the transitory components, and we assume that $\psi_{p}$ and $\kappa_{n p}$ are uncorrelated with $\varepsilon_{p \tau}$ and $\nu_{n p \tau}$ and $\varepsilon_{p \tau}$ and $\nu_{n p \tau}$ are serially uncorrelated.

It follows from (25) and (26) that all forecasts of future incomes of the parents depend only on $\tau_{p}, \boldsymbol{x}_{p}$, and $\psi_{p}$ and those for the income of daughters on $\tau_{n p}, \boldsymbol{x}_{n p}$, and $\kappa_{n p}$, while past realizations of income are functions of $\tau_{i}, \boldsymbol{x}_{i}(i=p, n p), \psi_{p}, \kappa_{n p}, \varepsilon_{p \tau}$ and $v_{n p \tau}$. Furthermore, it follows from the discussion in Section 2 that the threshold birth order that determines Regime $1, k_{p}^{*}$, also can be expressed as a function of these same error components, as well as $\pi_{N p}$. Exploiting these implications and approximating (19) and (20) as linear functions of the set of conditioning variables, we use the following representations of the decision rules for $t_{n p \tau}$ and $b_{n p a_{n}^{\prime}}$ in our empirical analyses:

$$
\begin{aligned}
t_{n p \tau}= & \alpha_{0}+\alpha_{1} b_{n p a_{n}^{\prime}}+\alpha_{2} n_{p \tau}+\alpha_{3} \tilde{\pi}_{N p}+\alpha_{4} N_{p}+\alpha_{5} A G_{n p \tau}+\alpha_{6} b_{n p a_{n}^{\prime}} \cdot n_{p \tau}+\alpha_{7} b_{n p a_{n}^{\prime}} \cdot n_{p \tau} \cdot A G_{n p \tau} \\
& +\zeta^{a} a_{n}+\mathbf{z}^{p \prime} \boldsymbol{x}_{p}+\sum_{j=1}^{N} \mathbf{z}_{j}^{n \prime} \boldsymbol{x}_{j p} \\
& +\eta^{\pi} \Delta \pi_{N p}+\eta^{\phi} \phi_{p}+\sum_{j=1}^{N} \eta_{j}^{\omega} \omega_{j p}+\eta^{\psi} \psi_{p}+\sum_{j=1}^{N} \eta_{j}^{\kappa} \kappa_{j p} \\
& +\sum_{i=0}^{\tau} \eta_{i}^{\varepsilon} \varepsilon_{p i}+\sum_{j=n+1}^{N} \sum_{i=a_{j}^{\prime}}^{\tau} \eta_{i j}^{v} \nu_{i p j}, \\
b_{n p a_{n}^{\prime}}= & \beta_{0}+\beta_{1} n_{p a_{n}^{\prime}}+\beta_{2} \tilde{\pi}_{N p}+\beta_{3} N_{p}+\beta_{4} A G_{n p a_{n}^{\prime}}+\beta_{5} n_{p a_{n}^{\prime}} \cdot A G_{n p a_{n}^{\prime}} \\
& +\theta^{a} a_{n}+\theta^{p \prime} \boldsymbol{x}_{p}+\sum_{j=1}^{N} \theta_{j}^{n \prime} \boldsymbol{x}_{j p} \\
& +\gamma^{\pi} \Delta \pi_{N p}+\sum_{j=1}^{N} \gamma_{j}^{\omega} \omega_{j p}+\gamma^{\psi} \psi_{p}+\sum_{j=1}^{N} \gamma_{j}^{\kappa} \kappa_{j p} \\
& +\sum_{i=0}^{a_{n}^{\prime}} \gamma_{i}^{\varepsilon} \varepsilon_{p i}+\sum_{j=n+1}^{N} \sum_{i=a_{j}^{\prime}}^{a_{n}^{\prime}} \gamma_{i j}^{v} \nu_{j p i},
\end{aligned}
$$


where $A G_{n p a_{n}^{\prime}}$ denotes the age-gap between the $n^{\text {th }}$ daughter and her next older sister who is under the age of $18, \tilde{\pi}_{N p}$ is an error-ridden measure of $\pi_{N p}, \Delta \pi_{N p}$ is its measurement error (i.e., $\pi_{N p}$ $\left.=\tilde{\pi}_{N p}+\Delta \pi_{N p}\right)$, and where the $\alpha$ 's, $\theta$ 's, $\gamma$ 's, $\beta$ 's, $\zeta$ 's, and $\eta$ 's are unknown parameters. The hypothesized reputation effects are characterized by the parameters $\alpha_{6}$ and $\beta_{1}$ for the parental transfer and daughter teen birth decisions, respectively, and the coefficients on the interactions with the age-gap variable, $\alpha_{7}$ and $\beta_{5}$, capture the reputation model's potential implications for how behavior may vary the more impatient are parents. We also augment the specifications in (27) and (27) by including a corresponding set of variables and interactions that measure the number of remaining brothers under age 18 (and the age-gap between a daughter and her next oldest brother under age 18) to assess the potential importance of parents establishing a reputation for being "tough" with their sons.

One could proceed by estimating the parameters in (27) and (28) using least squares methods, where the last two lines in each of these expressions are treated as composite error terms, denoted, say, by $u_{n p \tau}^{t}$ in (27) and $u_{n p a_{n}^{\prime}}^{b}$ in (28). But the orthogonality conditions for $u_{n p \tau}^{t}$ and $u_{n p a_{n}^{\prime}}^{b}$ with the observable determinants in (27) and (28) that are required for least squares are unlikely to hold for several reasons. First, the model of parent-daughter interactions implies that the $n^{\text {th }}$ daughter's teen birth decision, $b_{n p a_{n}^{\prime}}$, is influenced, in part, by the same unobserved components of daughters' preferences and those generating parental and daughters' income that directly enter the parental transfer equation through $u_{n p \tau}^{t}$. Thus, $b_{n p a_{n}^{\prime}}$, in (27) cannot be uncorrelated with $u_{n p \tau}^{t}$. Furthermore, to the extent that parental tastes for teenage childbearing, $\phi_{p}$, are correlated with unobserved parental tastes for their own fertility, both $u_{n p \tau}^{t}$ and $u_{n p a_{n}^{\prime}}^{b}$ would be 
correlated with the parents own fertility variables-i.e., $N_{p}, A G_{n p \tau}$, and, as a result, $n_{p \tau} \sqsubset$ that enter both (27) and (28). As such, estimation of the effects of these variables, and their interactions, also would be subject to endogeneity bias when using least squares methods.

In order to deal with these potential sources of endogeneity bias, we exploit two features of the NLSY79 to devise more robust estimators for the parameters in (27) and (28). The NLSY79 provide observations on daughters at different ages and data on multiple daughters of the same parents. These data allow us to implement two alternative "fixed-effects" estimation strategies. In the first, we exploit the multiple-sister data to devise "family-level fixed-effects" estimators of the parameters in (28) and (27). As discussed in Section 2, the reputation theory predicts that parents should punish, with probability one, their daughters who have teen births until the number of remaining sisters is less than or equal to the threshold, $k_{p}^{*}$, that defines the rounds of the game in Regime 1. That theory also indicates that $k_{p}^{*}$ depends on family-specific characteristics, including $\tilde{\pi}_{0 p}, \Delta \pi_{N p}, \phi_{p}, \psi_{p}, \delta_{p}$, and the $\omega_{n p}$ 's and $\kappa_{n p}$ 's for all daughters in the family. Therefore, the family fixed-effect estimator eliminates the influence of these familyspecific components, be they observable or unobservable in both (28) and (27). Moreover, the family fixed-effect estimator eliminates the impact of all the transitory income shocks that are realized before the oldest daughter (e.g., the $d^{\text {th }}$ daughter) in the family that is observed in the data makes her teen childbearing decision, i.e., it eliminates the $\varepsilon_{p i}$ 's and $v_{j p i}$ 's, for $i \leq a_{d}^{\prime}$ and $j=$ $d, \ldots, N$, in both (28) and (27). We present results for family fixed-effects estimators of the parameters for (28) and (27) below. ${ }^{25}$ Note that the coefficients on $n_{p \tau}$ (and its interactions) in (27) and (28), when controlling for family fixed-effects, are identified by the within-family temporal

\footnotetext{
${ }^{25}$ Below, we do report least squares estimates for the parameters in (27), largely for purposes of comparison with the family fixed-effect estimates.
} 
variation in this variable. This variation can come from either the birth of new daughters or the aging of daughters out of adolescence and into adulthood. In our context, almost all of the identification comes form the latter source of variation.

Using family fixed-effect estimators, however, does not account for time-varying unobservable factors that differ across sisters (daughters) in the same family. For example, family fixed-effects estimators do not account for differences across the information sets of two (or more) sisters at the time of their respective teen birth decisions. To account for between-sister differences, we also employ a "daughter-specific fixed-effects" estimator, exploiting the longitudinal data on each daughter in the same family. This second type of fixed-effects estimator accounts for the influence of family- and daughter-specific time-invariant unobservables. Daughter-specific fixed effects estimators also control for any information available up to the time when each daughter in a family makes her teen birth decision, i.e., at age $a_{n}^{\prime}$ for the $n^{\text {th }}$ daughter. This information includes all family-specific characteristics through age $a_{n}^{\prime}$ that would be eliminated by the family-specific fixed-effects estimator. As a result, the daughter-specific fixedeffects estimator accounts for the endogeneity of the $n^{\text {th }}$ daughter's teen birth outcome, $b_{n p a_{n}^{\prime}}$, in the parental transfer equation given in (27). Because of this latter property, the individual fixedeffects estimator is, a priori, our preferred estimator. ${ }^{26}$ Note, however, we can only employ the latter type of fixed-effect estimator when estimating the parental transfer equation; we cannot implement such an estimator for the parameters in (28) because there are no repeated observations on teen birth for a given daughter. ${ }^{27}$

\footnotetext{
${ }^{26}$ The work of Hotz, McElroy and Sanders (1999) on the effects of teenage childbearing suggests instrumental variables (IV) estimator for (27) in which whether or not a woman experiences a miscarriage as a teen is used as an instrument for the teen childbearing variable, $b_{n p}$.

${ }^{27}$ As with the family fixed-effects estimator, temporal variation in $n_{p \tau}$, due to daughters aging out of adolescence, identifies the coefficients on this variable (and its interactions) in (27) and (28).
} 
While the use of fixed-effects estimators-especially the daughter-specific fixed-effects variety — deal with all of the sources of bias that could arise in the specifications of the teen birth and parental transfer decisions given in (28) and (27), they may not be robust to certain generalizations of the specifications for these decision rules. For example, suppose that we allowed the tastes of parents (and daughters) to evolve over time (i.e., parents could learn about how they feel about their daughters having teen births) or that the time-varying stochastic components in (25) and (26) are serially correlated. With respect to tastes, it is possible that parental tastes with respect to the teenage childbearing of their daughters evolve over time, as parents gain experience with consequences of such births form their experiences with their older daughters. Similarly, a number of studies suggest that a permanent-transitory error structure is inadequate for characterizing the labor market earnings processes of individuals. ${ }^{28}$ Under either of these generalizations, our estimates of reputation effects derived for either set of fixed-effect estimators might still be biased. In an attempt to minimize these potential sources of bias, we control for an extensive set of observable time-varying parental and daughter-specific characteristics when estimating (28) and (27). For example, we include parental age, as of the time period when a particular daughter makes her teenage childbearing decision and/or when the parents are making a decision about transfers to a particular daughter, in both equations in order to proxy for the influence of time-varying factors determining parental income and/or the evolution of parental tastes. We also include daughter's age and other time-varying daughter-specific characteristics in our specifications of (28) and (27).

While failure to account for the above sorts of time-varying unobservables may bias our estimates of reputation effects, we note that such bias may be contrary to the implications of the

\footnotetext{
${ }^{28}$ See, for example, Lillard and Willis (1978) and Abowd and Card (1989), and Hirano (1998).
} 
reputation model. Consider the following potential source of such bias. Suppose that we fail to capture changes in parental or daughters' incomes over time due to unexpected changes of welfare policies, such as changes in AFDC benefits. If these policy changes provide greater benefits to those who have teen births and/or the amount of such benefits increases with the number of children under age 18, our estimates of estimates $\alpha_{2}$ and $\alpha_{6}$ in the parental transfer equation, for example, will capture both the effects of parental reputation and the impact of variation in welfare policies. To the extent that welfare programs like AFDC provide higher benefits for bigger families, we should observe more parental transfers to daughters who have teen births amongst families that have more daughters (or children) under age 18. Note that the bias imparted due to the latter effect is in exactly the opposite direction as the predicted effect of the number remaining daughters (or children) implied by our theory of parental reputation. As a result, the failure to adequately account for the impact of time-varying changes in welfare policy should lead to an under-estimate of the parental reputation effect.

\section{The Data}

This study uses data from the 1979 to 1994 waves of the National Longitudinal Survey of Youth 1979 (NLSY79). The NLSY79 consists of a nationally representative sample of youth in the U.S. between the ages of 14 to 21 in $1979 .{ }^{29}$ As noted above, we focus our analysis on the subset of the female respondents in the NLSY79 who have at least one sister in the sample. The NLSY79 sample design selected all children between the ages 14 and 21 (by January 1, 1979) who resided in surveyed households that were drawn in 1978. Of the 5,827 civilian female respondents originally included in the NLSY79, ${ }^{30} 1,697$ had one or more sisters in the NLSY79,

\footnotetext{
${ }^{29}$ For a complete description of this survey, see Bureau of Labor Statistics (1999).

${ }^{30}$ The NLSY79 also included a supplementary sample of women who were in the military at the time the sample was drawn. None of the women in this supplementary sample had sisters in the study.
} 
representing 782 families. Below, we discuss how this "multiple-sisters" sample we use in our empirical analyses differs from the sample of all NLSY79 female respondents.

The NLSY79 Survey gathered an extensive set of data on its female respondents in its 1979 baseline interview and in subsequent annual interviews through 1994. Included in this data are detailed fertility histories of female respondents as well as information about two forms of parental transfers to be described below. We also make use of the rich set of personal and family background characteristics gathered in the NLSY79 annual surveys.

The teen birth indicator, $b_{n p}$, used in the estimation of (28) and (27), is defined to be equal to 1 if a particular NLSY79 respondent (daughter) had a live birth prior to age 18. Based on this definition, we estimated the specification in (28) using one observation per daughter and measuring the time-varying variables, $n_{p \tau}, A G_{n p}$, and $\boldsymbol{x}_{p \tau}$, at age $\tau$, where this age is determined according to the age of first birth for daughters who had a teen birth or age 17 for daughters who did not have a birth prior to age 18 .

To assess the implications of the above reputation model, we analyze two alternative measures of parental transfers, $t_{n p \tau}$. The first is a dichotomous variable indicating whether a daughter's parents provided her with at least 50 percent of her annual expenses when she was age $t$, for $t>18$. We refer to this as the indicator of parental "financial transfers."

We used a dichotomous variable indicating whether the daughter was living in her parents' home in at a given age as a second measure of parental transfers, $t_{n p \tau}$. We refer to this as the parental "co-residence transfer." We note that the cash-equivalent of living with one's parents is not inconsequential as it entails free or low-cost room and board as well as the potential for free child care assistance for daughters who have births. Furthermore, among adult daughters who receive parental aid - particularly those who are poor or single mothers - the incidence of those re- 
ceiving such a co-residence transfer is much greater than that of receiving financial transfers from parents (see Rosenzweig and Wolpin, 1994; Hao and Brinton, 1997). At the same time, living with one's parents also entails less privacy and freedom and may involve non-financial obligations, such as providing assistance with household chores. Thus, it is not completely clear how daughters will value such residential transfers from parents and, as a consequence, how much "leverage" parents have through the provision and withholding of it from their daughters.

Variables key to the tests of the reputation effects-the number of sisters (brothers) under age 18, age gap between the daughter and the oldest sister (brother) in the risk set, and the daughter's prior belief about parents-are described in detail in Appendix A. The other variables used in the empirical specifications of (28) and (27) to control for differences in the family backgrounds, preferences of daughters and parents, and the context in which families make their decisions are described in Appendix A.

As noted above, we restrict our analyses to NLSY79 female respondents who had at least one other sister in the survey. Compared to the population of all parents, this multiple-daughter subsample over-represents daughters from large families. To examine how this subsample differs from the general population of families, we present, in Appendix B, means and standard deviations for the variables used in our financial transfer analyses for the multiple-daughter and allfamily samples. Beyond the anticipated differences in the average number of children and number of sisters (brothers) under age 18 noted above, the averages of the characteristics for the multiple-daughter subsample looks similar to those for the full sample of daughters. Parents in the multiple-daughter subsample are slightly wealthier, more educated, and more likely to be blacks than is the case for the families in the all-daughter sample. Moreover, parents in the multipledaughter sample are more likely to provide financial transfers to their daughters than is the case 
in the all-daughter sample. Thus, while the generalizability of the results presented below is limited to the behavior of multiple-daughter families, it is not apparent that this sample is particularly selective on other family characteristics.

\section{Results}

Before turning to our multivariate analysis, we examine the simple associations between our endogenous variables and number of sisters at risk (under age 18). Tables 1.1, 1.2, and 2 provide data on these associations for parental transfers and teenage childbearing, respectively. Throughout our empirical analysis, we present separate estimates by race of those relationships that are relevant to assessing the validity of our theory. We do so because there are marked differences in teenage childbearing rates between blacks and non-blacks and because previous ethnographic and sociological studies have found evidence to suggest that there are differences by race in the acceptance of teenage childbearing.

Table 1.1 and 1.2 present sample proportions by the teenage childbearing status of daughters and by the number of sisters under age 18 for parental financial and co-residence transfers. As one can see, on average, parents provide lower levels of financial transfers to daughters who become teen mothers than to daughters who do not have teen births. For example, among all races, $11 \%$ of daughters who are teen mothers receive financial transfers from parents, at ages older than 18 , while the corresponding figure is $22 \%$ for daughters who do not have a teen birth. Thus, the average parental "punishment" for teen childbearing is a decline in the likelihood of getting financial help from parents of .11 $(0.11-0.22)$. As can be seen in Table 1.2, parents also penalize daughters who have teen births by lowering the likelihood of providing housing to their daughters (.20 for daughters who have teen births versus .26 for daughters who do not) but the penalty is less. 
Note that the implication we draw from the reputation model of daughter-parent interactions over teenage childbearing concerns how these punishments change with the number of sisters at risk. How these punishments change with number of sisters under the age of 18 are displayed at the bottom of Tables 1.1 and 1.2. (See the entries under the "(1) Minus (2)" headings in both tables.) We do find that this penalty for teen childbearing does increase with the number of sisters under age 18 for both financial and residential transfers. For example, going from 0 to 1 sister under 18 increases the teen childbearing penalty from -0.10 to -0.19 on average, from -.07 to -.17 for blacks, and from -0.08 to -0.15 for non-blacks. The one exception is for residential transfers for non-blacks in Table 1.2, where there is a positive difference $(0.28)$ for those daughters who have 3 or more sisters under 18 . The latter may be due to the very small number of cell count, where there are only 5 daughters who had a teen birth in this three and more sisters category.)

The patterns shown at the bottom of both of these two tables are consistent with the predictions of the parental reputation model. However, they also are consistent with the fact that parental income may rise over the life cycle that could account for the greater likelihood of a transfer to younger daughters who have teen births. To better assess the validity of the reputation model's predictions, we need to examine the results that employ the econometric methods outlined in Section 4 that attempt to control for these alternative explanations.

Table 2 presents the sample proportions of teenage childbearing among daughters by the number of sisters under age 18 in the family. The data in Table 2 is not consistent with the predictions of the reputation model developed in Section 2.2. The incidence of teenage childbearing is substantially higher for women with at least three younger sisters compared to those with zero to two younger sisters, although there is much less difference across the zero, one and two cate- 
gories. The breakdowns by race show a similar pattern for blacks, even though the incidence of teenage childbearing are much higher. For non-blacks, we see a monotonic decline from zero to two sisters under age 18 but the trend reverses from two to three or more sisters under age 18. Thus, the extent to which the reputation story is relevant for teenage childbearing behavior, it must depend on our ability to control for the sorts of differences across families noted in our discussion of the econometric specification in Section 3.

Turning to the multivariate analysis, we present OLS and fixed-effects estimates in Tables 3, 4 and 5 for the parental financial and co-residence transfers decisions, and the teenage childbearing decisions, respectively. We present OLS estimates along with the fixed-effects estimators to provide a benchmark for what accounting for family- and individual-level sources of heterogeneity do to our estimates. In each of these tables, we provide only those parameter estimates (and marginal effects based on parameter estimates) most relevant for the reputation model or the alternative explanations noted above. ${ }^{31}$ All of the estimates were derived using the multiple-daughter sample described in Section 4.

Table 3 presents a selected set of estimates from the econometric specification in (27) for parental transfer decisions using the provision of financial transfers as our outcome measure. We present estimates for three different types of econometric estimators-OLS, family fixed-effects and individual fixed-effects estimators-using the multiple-daughter sample. Table 3 also presents results from three incremental models. Panel A serves as a baseline, where the reputation effect (captured by the number of sisters under 18) and the discount factor (captured by the agegap between the daughter and her oldest sisters under age 18) are tested. Panel B examines the additional reputation effect by using the number of brothers under age 18 and attempts to disen-

\footnotetext{
${ }^{31}$ A full set of estimates is available from the authors upon request.
} 
tangle the parental reputation effect from the influence of life cycle increases in parental income by including a measure of parental income and the age of the parents at the time of the transfer decision. Panel $\mathrm{C}$ examines the robustness of reputation effect by controlling for the number of sisters under age 18 who have had a teen birth.

According to our game theoretic model, parents' incentives to establish reputation imply that daughters who had a teen birth and have a large number of sisters remaining at risk are more likely to be punished. In other words, the greater the number of sisters under the age of 18 , the less likely is a daughter with a teen birth to receive financial transfers from parents. To test this hypothesis, we examine the coefficient on the interaction term between teenage childbearing and the number of sisters under age $18\left(b_{n p} \cdot n_{n p}\right)$ in Table 3. A consistent set of findings about the reputation effect emerges across the three estimators, throughout the three panels, and for blacks and non-blacks. In particular, we find that the coefficient on this interaction term is negative and that it tends to be statistically different from zero with high levels of precision. Note, too that while the estimated effect is larger, in absolute value, as one moves from OLS to the individual fixed-effects estimators, these changes are not sizeable. We also note that the estimated effect is not substantially different from that found in Table 1.1. Thus, based on this finding, there appears to be strong evidence of parental financial transfer responses to teenage childbearing that are consistent with the prediction regarding sisters remaining at risk suggested by the reputation model developed in Section 2.2.

How does parents' discounting of the future weaken the parental reputation effect? We examine the coefficient on the interaction term between teen birth, the number of sisters under 18 and the sister age gap $\left(b_{n p} \cdot n_{n p \tau} A G_{n p \tau}\right)$. Results from OLS throughout the three panels show a significant discounting effect; the discount is about $10 \%$ of the reputation effect. As one moves 
from OLS to family fixed-effects and individual fixed-effects estimators, the sign of the estimate remains positive and its magnitude remains similar but the estimate becomes less precise. This finding implies that the discount factor $\left(\delta_{p}\right)$ is close to one and parents' discounting of the future plays a minor role in their reputation building and disciplining their children remaining at risk.

Our theoretical prediction about parents' reputation concerns not only the undesirable behavior under investigation (teenage childbearing) but also other risky, undesirable behaviors. Parents punish teenage childbearing in order to prevent undesirable behaviors from occurring to at-risk younger children, girls and boys. To test this possibility, we include the number of brothers under 18 and its relevant interaction terms in Panel B. The estimate of this added reputation effect (captured by the interaction between teen birth and the number of brothers under 18) is negative and significant for both blacks and non-blacks in all three estimators. The effect is of the similar size as that found in the sister measure. This is evident that parents' motivation to build reputation and to discipline children is broad covering an array of undesirable behaviors rather than narrow with a specific undesirable behavior. The discount factor in terms of the brother measure is not significantly different from one.

Panel $\mathrm{B}$ also tests the possibility that the reputation effect might be biased by the failure to account for life cycle increases in parental income. As already noted, increases in parental income over their life cycle would lead to an estimated effect of number of remaining sisters that is of the same sign as the effect implied by our parental reputation model. To help separate the latter life cycle income effect from the reputation effect, we include in Panel B an interaction term between teen birth, the number of siblings under 18 and family income (and all relevant lowerorder interaction terms). If the estimate of the effect of number of remaining siblings is picking up, in part, the impact of life cycle increases in parental income, we should expect to find a sig- 
nificant, positive coefficient on this interaction term. The coefficient on this interaction is insignificant and close to zero, providing a stronger test of the parental reputation effect by disentangling it from the influence of life cycle increases in parental income.

In Panel $\mathrm{C}$ we went further along the line of specific undesirable behavior in parents' motivation of reputation building. We have been measuring "at risk" by the number of sisters (brother) under 18, the age range of minor children under the ward of parents. If the reputation is specific to teenage childbearing, we should disregard those sisters who have had a teen birth. Thus we add a parallel set of variables using the number of sisters under 18 with a teen birth. If the motivation for specific behavior (teenage childbearing) is right, we should see a significant, positive coefficient on the interaction between teen birth and the number of sisters under 18 with a teen birth. Instead, we see a negative coefficient. It is insignificant for blacks but significant and sizable for non-blacks. Two implications are possible. First, it further suggests the broadoriented motivation of reputation building by parents for both blacks and non-blacks. Second it implies that non-black parents are more alert to multiple incidences of teenage childbearing and act harsher than black parents.

Our analysis from Panel A to Panel C provides three pieces of strong evidence to support our game theoretic prediction about parental reputation effects. First the reputation effect is significant and sizable for both blacks and non-blacks. Second, the reputation effect is broadlyoriented rather than specifically-oriented, as exhibited in both the number of sisters and brothers remaining at risk and the lack of sensitivity to the number of sisters under age 18 with a teen birth. Third, the reputation effect remains strong and significant when we include our measure of parental income with the number of sisters under age 18.

We perform a parallel set of analyses using parental co-residence transfers as the out- 
come. The corresponding estimates are presented in Table 4, with the format being the same as that in Table 3. Comparing the results in Tables 3 and 4, we find several similarities and differences. The similar patters include (1) the persistent negative sign of the reputation effect, captured by the interaction between teen birth and the number of sisters (brothers) under 18; (2) the estimated effect of the number of remaining sisters under age 18 does not seem to be the result of increases in parental income as parents get older; and (3) the parental reputation effect is not sensitive to the number of sisters under 18 with a teen birth. However, we find a few noticeable differences. First, the coefficient on the interaction between teen birth and the number of sisters under 18 tends to be weaker and less stable than that on financial transfers. Second, for financial transfers, we find a similar and significant reputation effect for non-blacks and blacks. But for co-residence transfers, the reputation effect captured by the interaction between teen birth and the number of sisters under 18 in Panel A is stronger and more significant for non-blacks than for blacks. Third, whereas the discounting effect is close to one in the financial transfer equation, the discounting effect has a wrong sign, albeit insignificant, in the co-residence transfer equation. Overall, the estimated parental reputation effect on co-residence transfers shows less consistency with the reputation model with less precision than the estimated reputation effect on financial transfers. As we discussed in Section 2, co-residence transfers are complicated by the potential parent-child conflict and a loss of privacy, our reputation model does not fully take into account this more complicated process than in the case of financial transfers.

Finally, we turn to the results for a daughter's teenage childbearing decision, presented in Table 5. As before, we present both OLS and fixed-effects estimates (with only family fixedeffects estimates since we have only one observation for each daughter's teenage childbearing behavior). Panel A testes the parental reputation effect by the number of sisters (brothers) under 
18 and Panel B tests the sensitivity to the number of sisters under 18 with a teen birth. The primary implication from our reputation model is that the greater the number of sisters (brothers) under 18 , the less likely a daughter will have a teen birth. Overall, the results are quite unstable. For example, in Panel A, the results from the OLS estimator and the family fixed-effects estimator yield the same negative sign for the number of sisters under 18 with low precision. This lack of significance of the reputation effect may reflect the lack of statistical power to detect the effect due to the relatively smaller number of observations as compared to the transfer analysis. The reputation effect captured by the number of brothers under 18 has an opposite sign to our expectation and significant for blacks. We suspect that this effect may be attributable to the distinctive relationship between parents and sons for blacks.

More noticeably, the parental reputation effect is not sensitive to the number of sisters under 18 with a teen birth in the OLS estimator but very sensitive in the family fixed-effects estimator (see Panel B). Based on the reputation model, forgiving parents are likely to punish these sisters with a teen birth right away by withholding transfers or other disciplinary measures in order to send a strong signal to their other at-risk daughters that teen childbearing is unacceptable. While we do not have data on how parents immediately react to teen births, our results from the analysis on financial transfers during adult years suggest that such punishment may have occurred. Thus, we would expect that, when daughters make decisions on teenage childbearing, experiencing the reaction of their parents to the incidence of teen births of their sisters would reduce the probability of teenage childbearing. According to the fixed-effects estimate in Panel B, it appears that, for both blacks and non-blacks, the incidence of teenage childbearing having already occurred to sisters serves as a strong signal from the parents that such behavior is very wrong. Such a signaling effect is so strong that it overshadows the parental reputation effect. 


\section{Conclusions}

In this paper, we have examined the empirical implications of parental reputation formation in a game-theoretic model of interactions between parents and their daughters over the teenage childbearing decisions of daughters and the transfer responses of parents to those decisions. Our investigation focuses on a circumstance where the family fails to act as a unitary actor. We recognize that the family internalizes parental values and norms through socialization, supervises children's behavior through positive and negative sanctioning, and internalizes externalities through unitary decision-making. However, children's undesirable behavior, such as teenage childbearing, occurs and parents have incentives to establish reputation in order to prevent such undesirable behavior from occurring to their younger children. Our paper addresses the parentdaughter interactions under this circumstance. Drawing on the theory of reputation in repeated games by Milgrom and Roberts (1982) and Kreps and Wilson (1982), we show that parents have, under certain conditions, the incentive to penalize teenage (and typically out-of-wedlock) childbearing of older daughters, in order to get the younger daughters to avoid teenage childbearing, or to get the younger children to avoid undesirable behavior in general. While such differential treatment does not result in pareto-efficient decision-making by the family, the use of reputation by parents may improve upon an altruistic-headed family's allocations of resources and child behavioral outcomes.

The two key empirical implications of our game theoretic model is that the likelihood of teenage childbearing and parental transfers to daughters who have had teen births will decrease with the number of sisters (brothers) under 18. In the paper, we tested these two implications, using data from the National Longitudinal Survey of Youth, 1979 Cohort (NLSY79). We exploited the availability of repeated observations on young women (daughters) and of observations on 
multiple daughters (sisters) available in the NLSY79 to use family and individual fixed-effects estimators in order to control for the possibility of endogeneity and omitted variable bias when conducting tests for the parental reputation effect. Based on these methods, we find strong evidence of parental financial transfer responses to teenage childbearing by the number of sisters (brothers) under 18 for both blacks and non-blacks. Moreover, these estimated effects do not seem to be explained by the fact parents have higher incomes when their younger daughters become of age to have teen births due to life cycle changes in parental income. Rather, our findings appear to be quite consistent with the implications of parents establishing reputations for being unforgiving of daughters bearing children as teens. While the findings for co-residence transfers and teenage childbearing decisions are weaker, they suggest the mechanism of parents' reputation formation. Further testing, which examines other risky teenage behaviors and exploits more of the structure of the game-theoretic model motivating this work, will be the focus of future work. 


\section{References}

Abowd, J. and D. Card (1989), "On the Covariance Structure of Earnings and Hours Changes," Econometrica, 57(2), 411-445.

Akerloff, G., J. Yellen, and M. Katz (1996), “An Analysis of Out-of-Wedlock Childbearing in the United States," Quarterly Journal of Economics, 111(2):277-317.

Anne E. Casey Foundation, (1999), When Teens Have Sex: Issues and Trends-A KIDS COUNT Special Report, Baltimore.

Becker, G. (1991), A Treatise on the Family, Enlarged Edition, Cambridge, MA: Harvard University Press.

Bergstrom, T. (1989), "A Fresh Look at the Rotten Kid Theorem-and Other Household Mysteries," Journal of Political Economy, 5 (October), 1138-1159.

Brien, M. and R. Willis (1997), "The Costs and Consequences of Early Fatherhood: The Impact on Young Men, Young Women, and Their Children," in Kids having Kids: The Economic Costs and Social Consequences of Teen Pregnancy, ed. by R. Maynard, Urban Institute Press.

Brooks-Gunn, J. and F. Furstenberg (1989), “Adolescent Sexual Behavior,” American Psychologist, 44(2), 249-257.

Browning, M. and P.-A. Chiappori (1998), "Efficient Intra-Household Allocations: A General Characterization and Empirical Tests," Econometrica, 66(6), 1241-1278.

Bruce, N. and M. Waldman (1990), “The Rotten-Kid Theorem Meets the Samaritan's Dilemna," Quarterly Journal of Economics, 105(1), 155-165.

Bureau of Labor Statistics (1999), NLS Handbook, U.S. Department of Labor, U.S. Government Printing Office.

Card, J.J. (1981), “The Long-Term Consequences for Children of Teenage Parents," Demography, 18(2), 137-156.

Gordon, L. (1997), “Teenage Pregnancy and Out-of-Wedlock Birth,” in Morality and Health, ed. Brandt and Rozin, Stanford: Stanford University Press.

Hao, L. and M. Brinton (1997), "Productive Activities and Support Systems of Single Mothers." American Journal of Sociology, 102(5):1305-1344.

Hayes, C. (1987), Risking the Future, Volume 1, Washington, DC: National Academy Press.

Hirano, K. (1998), “A Semiparametric Model for Labor Earnings Dynamics,” in Practical Nonparametric and Semiparametric Bayesian Statistics, ed. by D. Dey, P. Mueller, and D. Sinha, New York: Springer-Verlag. 
Hirshleifer, J. (1985), “The Expanding Domain of Economics," American Economic Review, LXXV, 53-68.

Hirshleifer, J. (1997), "Shakespeare Versus Becker on Altruism: The Importance of Having the Last Word," Journal of Economic Literature, XV, 500-502.

Hotz, V. J., S. McElroy and S. Sanders (1999), “Teenage Childbearing and Its Life Cycle Consequences: Exploiting a Natural Experiment," Unpublished manuscript, UCLA, August.

Hotz, V. J., S. Mullin, and S. Sanders (1997), "Bounding Causal Effects Using Data from a Contaminated Natural Experiment: Analyzing the Effects of Teenage Childbearing," Review of Economic Studies, 64, 575-603.

Kane, T. and D. Staiger (1996), “Teen Motherhood and Abortion Access," Quarterly Journal of Economics, 111(2):467-506.

Kreps, D. and R. Wilson (1982), "Reputation and Imperfect Information," Journal of Economic Theory, 27, 253-279.

Lillard, L. and R. Willis (1978), "Dynamic Aspects of Earnings Mobility," Econometrica, 46, 985-1012.

Lindbeck, A. and J. Weibull (1988), "Altruism and Time Consistency: The Economics of Fait Accompli," Journal of Political Economy, 96(6), 1165-1182.

Luker, K. (1996), Dubious Conceptions: The Politics of Teenage Pregnancy, Cambridge: Harvard University Press.

Milgrom, P. and J. Roberts (1982), "Predation, Reputation and Entry Deterrence," Journal of Economic Theory, 27, 280-312.

Moore, K., J. Peterson and F. Furstenberg (1986), "Parental Attitudes and the Occurrence of Early Sexual Activity," Journal of Marriage and the Family, 48, 777-782.

Mullin, C. (1998), A Re-Evaluation of Teenage Childbearing, Unpublished Dissertation, University of Chicago.

Nechyba, T. (1999), "Social Approval, Values and AFDC: A Re-Examination of the Illegitimacy Debate," NBER Working Paper 7240, July.

Pirog-Good, M. and D. Good (1995), “Child Support Enforcement for Teenage Fathers: Problems and Prospects," Journal of Policy Analysis and Management, 14(1):25-42.

Rosenzweig, M. and K. Wolpin. (1994), "Parental and Public Transfers to Young Women and Their Children," American Economic Review 84:1195-1212.

Selten, R. (1978), “The Chain-Store Paradox,” Theory and Decision, 9, 127-159. 
Upchurch, D. and J. McCarthy (1990), “The Timing of a First Birth and High School Completion," American Sociological Review, 55, 224-234. 


\section{Case 1: Forgiving Parents}

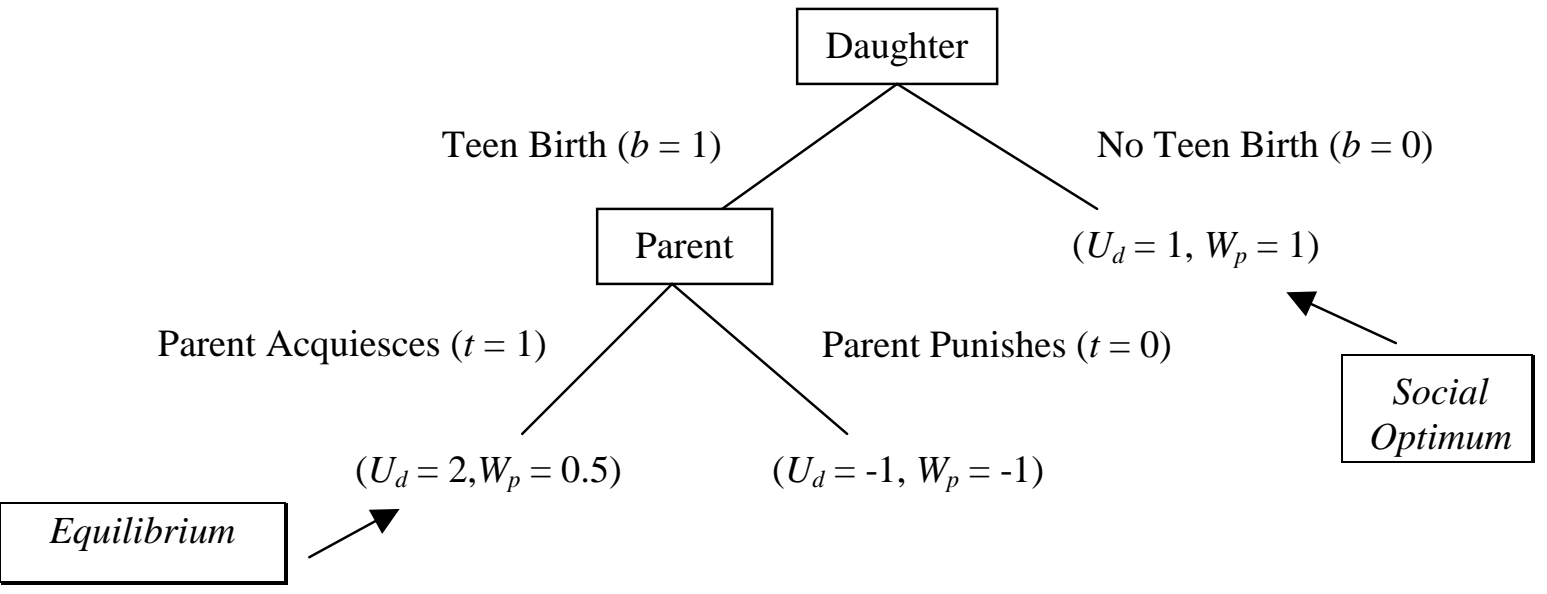

Case 2: Unforgiving Parents

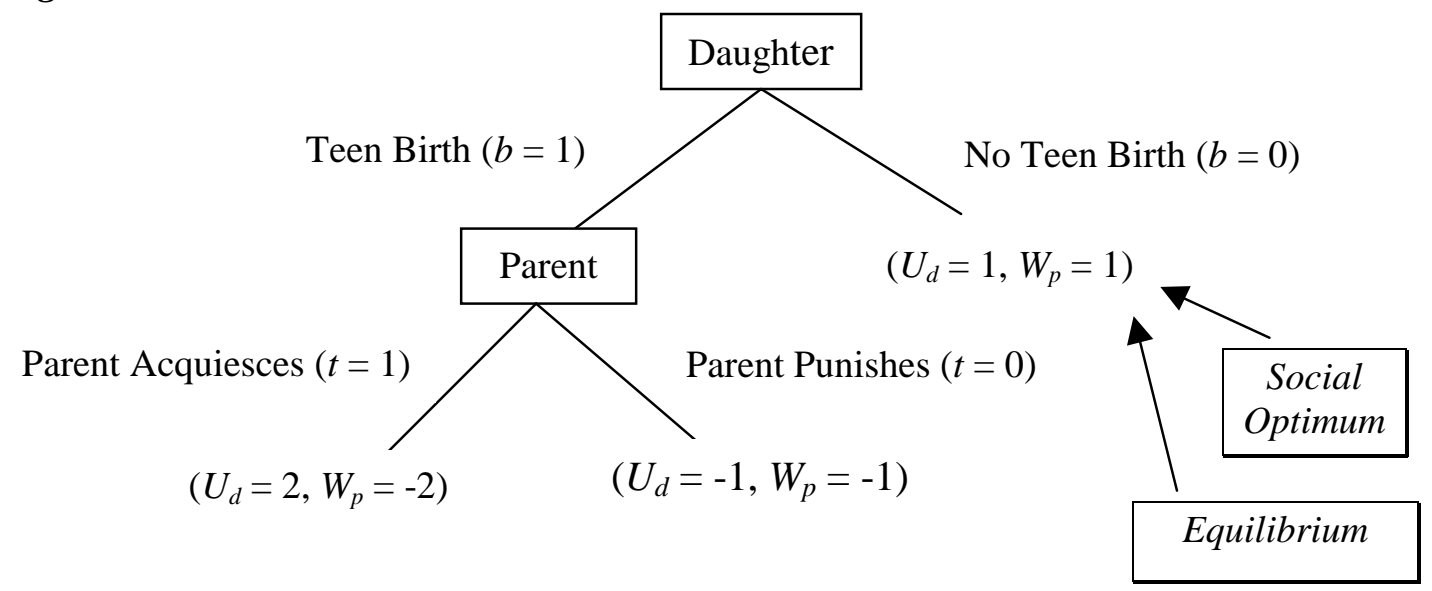

Figure 1: Decision Tree for Parents' and Daughter's Decisions 
Panel 1: Daughters' Prior Belief of the Probability of Having a Forgiving Parent $\left(\pi_{N}\right)$ and the Definition of $k^{*}$

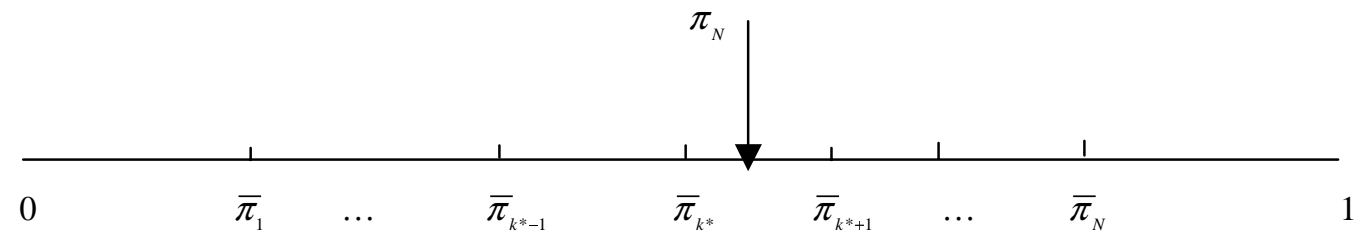

Panel 2: Forgiving Parent's Transfer Strategy, t(b), by the Number of Remaining Daughters in the Game (n)

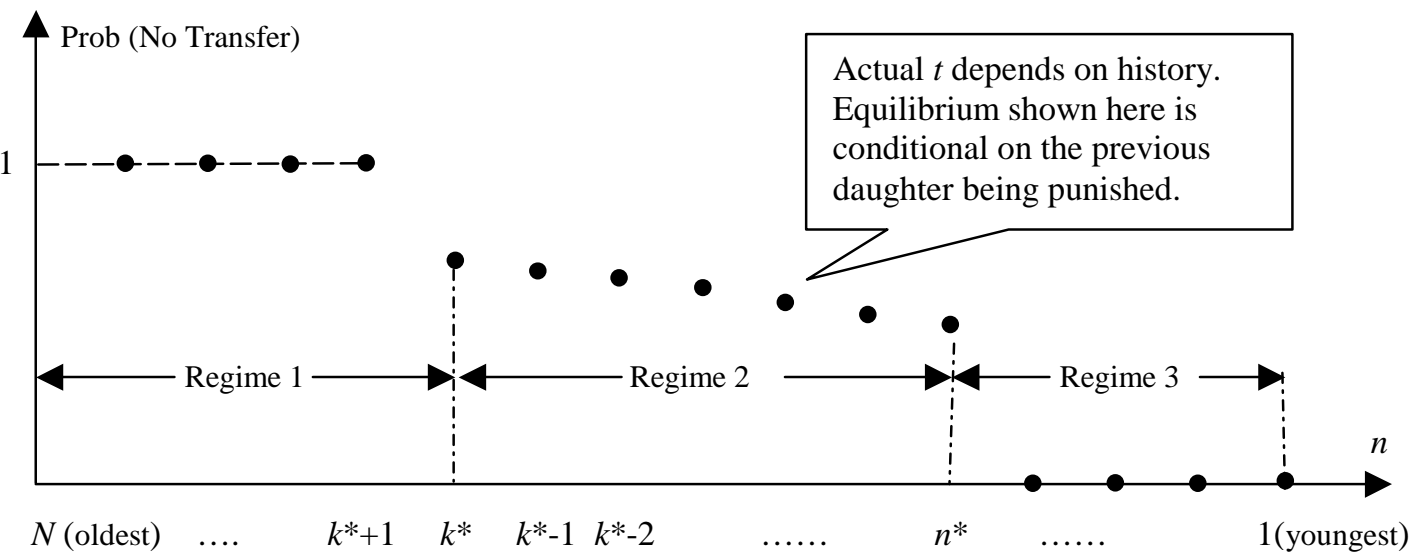

Panel 3: Teenage Childbearing Strategy of Daughters, by the Number of Remaining Daughters in the Game (n)

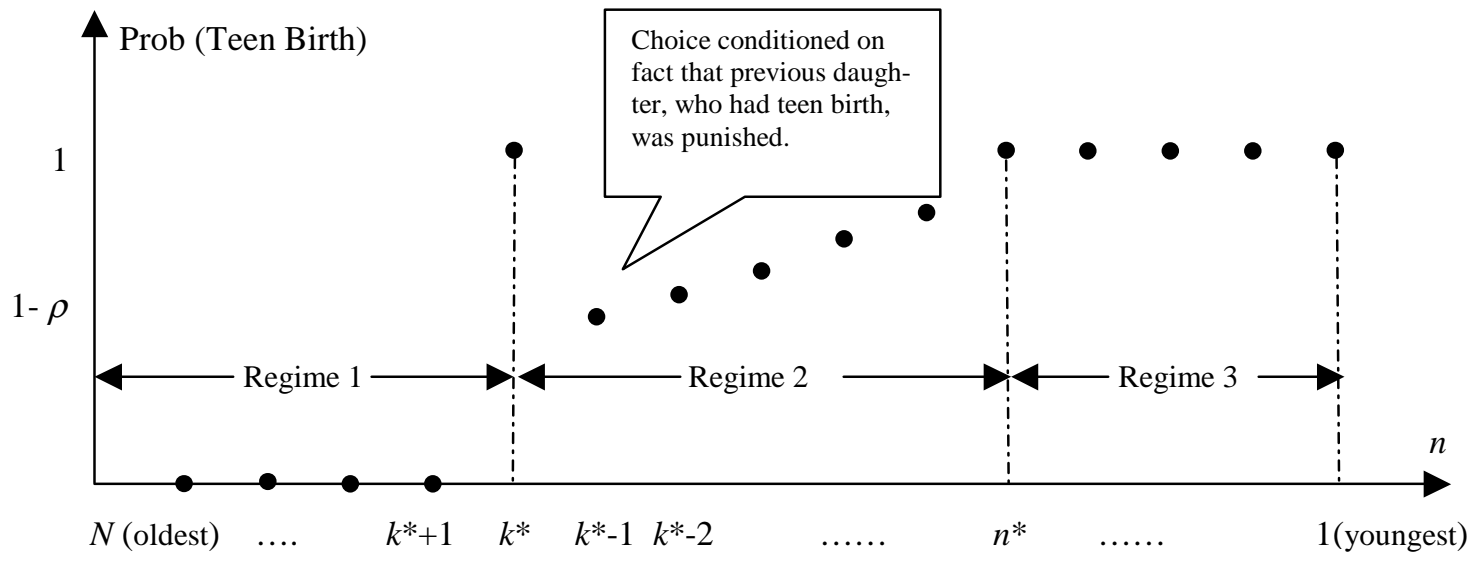

Figure 2: Features of the Solution to the Daughters-Parent Repeated Game with Reputation Effects 


\section{Table 1.1: Parental Financial Transfers by Teenage Childbearing, Race, and Number of Younger Daughters Under 18}

\begin{tabular}{|c|c|c|c|c|c|c|}
\hline \multirow[t]{2}{*}{ Conditions } & \multicolumn{2}{|c|}{ Total } & \multicolumn{2}{|c|}{ Black } & \multicolumn{2}{|c|}{ Non-Black } \\
\hline & Mean & $N$ & Mean & $N$ & Mean & $N$ \\
\hline \multicolumn{7}{|l|}{ Teenage Childbearing Status } \\
\hline No teenage childbearing & 0.22 & 12,200 & 0.20 & 3,217 & 0.23 & 8,983 \\
\hline Had teenage childbearing & 0.11 & 1,418 & 0.10 & 848 & 0.13 & 570 \\
\hline Total & 0.22 & 13,618 & 0.18 & 4,065 & 0.22 & 9,553 \\
\hline \multicolumn{7}{|l|}{ (1) Teenage Childbearing } \\
\hline \multicolumn{7}{|l|}{ Number of sisters under 18} \\
\hline 0 & 0.09 & 861 & 0.08 & 582 & 0.11 & 279 \\
\hline 1 & 0.15 & 211 & 0.12 & 151 & 0.20 & 60 \\
\hline 2 & 0.16 & 110 & 0.20 & 61 & 0.12 & 49 \\
\hline $3+$ & 0.31 & 42 & 0.18 & 37 & 0.92 & 5 \\
\hline Missing & 0.07 & 194 & 0.05 & 17 & 0.07 & 177 \\
\hline \multicolumn{7}{|l|}{ (2) No Teenage Childbearing } \\
\hline \multicolumn{7}{|l|}{ Number of sisters under 18} \\
\hline 0 & 0.18 & 7,568 & 0.15 & 2,029 & 0.19 & 5,539 \\
\hline 1 & 0.34 & 2,094 & 0.29 & 720 & 0.35 & 1,374 \\
\hline 2 & 0.41 & 569 & 0.43 & 150 & 0.41 & 419 \\
\hline $3+$ & 0.56 & 117 & 0.56 & 38 & 0.56 & 79 \\
\hline Missing & 0.21 & 1,852 & 0.19 & 280 & 0.21 & 1,572 \\
\hline \multicolumn{7}{|l|}{ (1) Minus (2) } \\
\hline Number of sisters under 18 & & & & & & \\
\hline 0 & $-0.10^{123}$ & & $-0.07^{123}$ & & $-0.08^{23}$ & \\
\hline 1 & $-0.19^{0}$ & & $-0.17^{03}$ & & $-0.15^{3}$ & \\
\hline 2 & $-0.25^{0}$ & & $-0.23^{0}$ & & $-0.29^{03}$ & \\
\hline $3+$ & $-0.25^{0}$ & & $-0.38^{01}$ & & $0.36^{012}$ & \\
\hline
\end{tabular}

Notes: Sampling weights were used to reproduce the population distribution of means and standard deviations.

The superscript "numbers" on the table entries denote which differences in means by number of younger daughters under 18 are significantly different at the .10 level. For example, a code of " 03 " beside -0.29 indicates that this mean is significantly different from the means for 0 remaining sister and 3 remaining daughters. 


\section{Table 1.2: Parental Co-Residence Transfers by Teenage Childbearing, Race, and Number of Younger Daughters Under 18}

\begin{tabular}{|c|c|c|c|c|c|c|}
\hline \multirow[t]{2}{*}{ Conditions } & \multicolumn{2}{|c|}{ Total } & \multicolumn{2}{|c|}{ Black } & \multicolumn{2}{|c|}{ Non-black } \\
\hline & Mean & $N$ & Mean & $N$ & Mean & $N$ \\
\hline \multicolumn{7}{|l|}{ Teenage Childbearing Status } \\
\hline No teenage childbearing & 0.26 & 19,747 & 0.35 & 5,289 & 0.25 & 14,458 \\
\hline Had teenage childbearing & 0.20 & 2,343 & 0.26 & 1,425 & 0.14 & 918 \\
\hline Total & 0.26 & 22,090 & 0.33 & 6,714 & 0.25 & 15,376 \\
\hline \multicolumn{7}{|l|}{ (1) Teenage Childbearing } \\
\hline \multicolumn{7}{|l|}{ Number of sisters under 18} \\
\hline 0 & 0.19 & 1,535 & 0.24 & 1,022 & 0.13 & 513 \\
\hline 1 & 0.36 & 252 & 0.42 & 177 & 0.25 & 75 \\
\hline 2 & 0.22 & 126 & 0.27 & 73 & 0.16 & 53 \\
\hline $3+$ & 0.45 & 45 & 0.35 & 40 & 0.92 & 5 \\
\hline Missing & 0.11 & 385 & 0.13 & 113 & 0.09 & 272 \\
\hline \multicolumn{7}{|l|}{ (2) No Teenage Childbearing } \\
\hline \multicolumn{7}{|l|}{ Number of sisters under 18} \\
\hline 0 & 0.24 & 13,250 & 0.32 & 3,611 & 0.22 & 9,639 \\
\hline 1 & 0.44 & 2,380 & 0.49 & 795 & 0.43 & 1,585 \\
\hline 2 & 0.57 & 586 & 0.61 & 154 & 0.56 & 432 \\
\hline $3+$ & 0.69 & 118 & 0.88 & 38 & 0.64 & 80 \\
\hline Missing & 0.20 & 3,413 & 0.25 & 691 & 0.19 & 2,722 \\
\hline \multicolumn{7}{|l|}{ (1) Minus (2) } \\
\hline \multicolumn{7}{|l|}{ Number of sisters under 18} \\
\hline 0 & $-0.05^{23}$ & & $-0.08^{23}$ & & $-0.09^{2}$ & \\
\hline 1 & $-0.08^{2}$ & & $-0.07^{23}$ & & $-0.18^{2}$ & \\
\hline 2 & $-0.35^{01}$ & & $-0.34^{01}$ & & $-0.40^{013}$ & \\
\hline $3+$ & $-0.24^{0}$ & & $-0.53^{01}$ & & $0.28^{2}$ & \\
\hline
\end{tabular}

Notes: Sampling weights were used to reproduce the population distribution of means and standard deviations.

The superscript "numbers" on the table entries denote which differences in means by number of younger daughters under 18 are significantly different at the .10 level. For example, a code of " 23 " beside -0.06 indicates that this mean is significantly different from the means for 2 remaining sister and 3 remaining daughters. 
Table 2: Teenage Childbearing by Race, and Younger Daughters Under 18

\begin{tabular}{|c|c|c|c|c|c|c|}
\hline \multirow[t]{2}{*}{ Conditions } & \multicolumn{2}{|c|}{ Total } & \multicolumn{2}{|c|}{ Black } & \multicolumn{2}{|c|}{ Non-Black } \\
\hline & Mean & $N$ & Mean & $N$ & Mean & $\bar{N}$ \\
\hline Number of sisters under 18 & & & & & & \\
\hline 0 & 0.07 & 393 & 0.17 & 113 & 0.05 & 280 \\
\hline 1 & 0.07 & 560 & 0.22 & 179 & 0.04 & 381 \\
\hline 2 & 0.06 & 288 & 0.23 & 99 & 0.02 & 189 \\
\hline $3+$ & 0.11 & 53 & 0.26 & 62 & 0.06 & 91 \\
\hline Missing & 0.04 & 295 & 0.05 & 51 & 0.04 & 244 \\
\hline Total & 0.07 & 1,689 & 0.20 & 504 & 0.04 & 1,185 \\
\hline
\end{tabular}

Note: The sample consists of daughters from multiple biological daughter families in the NLSY79. Sampling weights were used to reproduce the population distribution of means and standard deviations. 
Table 3: Determinants of Parental Financial Transfers

[Dependent Variable: Whether Daughter Received Financial Transfer from Parents at Age $t$;

Sample: Families with 2-4 Daughters; Data Source: NLSY79]

\begin{tabular}{|c|c|c|c|}
\hline Variables & OLS & $\begin{array}{c}\text { Family } \\
\text { Fixed-Effects }\end{array}$ & $\begin{array}{c}\text { Daughter } \\
\text { Fixed-Effects }\end{array}$ \\
\hline \multicolumn{4}{|l|}{ Panel A: } \\
\hline Teen birth & $\begin{array}{l}-.0462 * * \\
(.0203)\end{array}$ & $\begin{array}{l}-.0118 \\
(.0268)\end{array}$ & \\
\hline Teen birth $\times$ Black & $\begin{array}{l}.0269 \\
(.0235)\end{array}$ & $\begin{array}{l}-.0045 \\
(.0329)\end{array}$ & \\
\hline No. of sisters under 18 & $\begin{array}{l}.0286 * * * \\
(.0074)\end{array}$ & $\begin{array}{l}.0257 * * * \\
(.0091)\end{array}$ & $\begin{array}{l}.0271 * * * \\
(.0095)\end{array}$ \\
\hline No. of brothers under 18 & $\begin{array}{l}-.0046 \\
(.0070)\end{array}$ & $\begin{array}{l}-.0098 \\
(.0094)\end{array}$ & $\begin{array}{l}-.0107 \\
(.0097)\end{array}$ \\
\hline Age-gap between daughter and her oldest sister under 18 & $\begin{array}{l}-.0020 * \\
(.0012)\end{array}$ & $\begin{array}{l}.0001 \\
(.0016)\end{array}$ & $\begin{array}{l}.0014 \\
(.0019)\end{array}$ \\
\hline Age-gap between daughter and her oldest brother under 18 & $\begin{array}{l}.0005 \\
(.0011)\end{array}$ & $\begin{array}{l}.0004 \\
(.0016)\end{array}$ & $\begin{array}{l}.0026 \\
(.0019)\end{array}$ \\
\hline Teen Birth $\times$ Sister age-gap & $\begin{array}{l}-.0060 \\
(.0049)\end{array}$ & $\begin{array}{l}-.0014 \\
(.0069)\end{array}$ & $\begin{array}{l}-.0045 \\
(.0097)\end{array}$ \\
\hline Teen Birth $\times$ No. sisters under 18 , Non-Blacks & $\begin{array}{l}-.1076 * * * \\
(.0279)\end{array}$ & $\begin{array}{l}-.1174 * * * \\
(.0340)\end{array}$ & $\begin{array}{l}-.1665 * * * \\
(.0455)\end{array}$ \\
\hline Teen Birth $\times$ No. sisters under 18 , Blacks & $\begin{array}{l}-.1196 * * * \\
(.0250)\end{array}$ & $\begin{array}{l}-.1430 * * * \\
(.0283)\end{array}$ & $\begin{array}{l}-.1757^{* * * *} \\
(.0343)\end{array}$ \\
\hline Teen Birth $\times$ No. sisters under $18 \times$ Sister age-gap & $\begin{array}{l}.0143 * * * \\
(.0043)\end{array}$ & $\begin{array}{c}.0104 * \\
(.0060)\end{array}$ & $\begin{array}{c}.0132 \\
(.0095)\end{array}$ \\
\hline \multicolumn{4}{|l|}{ Panel B: } \\
\hline Teen birth & $\begin{array}{l}-.0475 * * \\
(.0236)\end{array}$ & $\begin{array}{l}-.0347 \\
(.0314)\end{array}$ & \\
\hline Teen birth $\times$ Black & $\begin{array}{c}.0468^{*} \\
(.0250)\end{array}$ & $\begin{array}{l}.0194 \\
(.0347)\end{array}$ & \\
\hline No. of sisters under 18 & $\begin{array}{l}.0205 * * \\
(.0081)\end{array}$ & $\begin{array}{l}-.0018 \\
(.0101)\end{array}$ & $\begin{array}{l}-.0012 \\
(.0106)\end{array}$ \\
\hline No. of brothers under 18 & $\begin{array}{l}.0015 \\
(.0083)\end{array}$ & $\begin{array}{l}-.0188 \\
(.0111)\end{array}$ & $\begin{array}{l}-.0159 \\
(.0117)\end{array}$ \\
\hline Age-gap between daughter and her oldest sister under 18 & $\begin{array}{l}-.0022^{*} \\
(.0012)\end{array}$ & $\begin{array}{l}-.0002 \\
(.0017)\end{array}$ & $\begin{array}{l}.0009 \\
(.0019)\end{array}$ \\
\hline Age-gap between daughter and her oldest brother under 18 & $\begin{array}{l}-.0007 \\
(.0011)\end{array}$ & $\begin{array}{l}-.0012 \\
(.0017)\end{array}$ & $\begin{array}{l}.0015 \\
(.0020)\end{array}$ \\
\hline Teen birth $\times$ Sister age-gap & $\begin{array}{l}-.0020 \\
(.0053)\end{array}$ & $\begin{array}{l}-.0006 \\
(.0071)\end{array}$ & $\begin{array}{l}-.0020 \\
(.0098)\end{array}$ \\
\hline Teen birth $\times$ Brother age-gap & $\begin{array}{l}.0052 \\
(.0035)\end{array}$ & $\begin{array}{l}.0062 \\
(.0041)\end{array}$ & $\begin{array}{l}.0043 \\
(.0057)\end{array}$ \\
\hline Teen birth $\times$ No. of sisters under 18 , Non-blacks & $\begin{array}{l}-.0832 * * \\
(.0328)\end{array}$ & $\begin{array}{l}-.0679 * \\
(.0400)\end{array}$ & $\begin{array}{l}-.1232 * * \\
(.0558)\end{array}$ \\
\hline Teen birth $\times$ No. of brothers under 18 , Blacks & $\begin{array}{l}-.1136 * * * \\
(.0276)\end{array}$ & $\begin{array}{l}-.1075 * * * \\
(.0322)\end{array}$ & $\begin{array}{l}-.1156^{* * * *} \\
(.0417)\end{array}$ \\
\hline Teen birth $\times$ No. of sisters under $18 \times$ Sister age-gap & $\begin{array}{l}.0095 * * \\
(.0047)\end{array}$ & $\begin{array}{l}.0066 \\
(.0061)\end{array}$ & $\begin{array}{l}.0093 \\
(.0096)\end{array}$ \\
\hline $\begin{array}{l}\text { Teen birth } \times \text { No. of brothers under } 18 \text {, Non-blacks } \\
\text { Teen birth } \times \text { No. of brothers under } 18 \text {, Blacks }\end{array}$ & $\begin{array}{l}-.1099 * * \\
(.0338) \\
-.1018 * * * \\
(.0241)\end{array}$ & $\begin{array}{l}-.1074 * * * \\
(.0388) \\
-.1068 * * * \\
(.0277)\end{array}$ & $\begin{array}{l}-.0904 * \\
(.0470) \\
-.1347 * * * \\
(.0317)\end{array}$ \\
\hline $\begin{array}{l}\text { Teen birth } \times \text { No. of brothers under } 18 \times \text { Brother age-gap } \\
\text { Teen birth } \times \text { No. of siblings under } 18 \times \text { Family income }\end{array}$ & $\begin{array}{c}.0037 \\
(.0027) \\
.0013 \\
(.0012) \\
\end{array}$ & $\begin{array}{l}.0011 \\
(.0034) \\
.0004 \\
(.0015) \\
\end{array}$ & $\begin{array}{l}.0011 \\
(.0042) \\
-.0004 \\
(.0020) \\
\end{array}$ \\
\hline
\end{tabular}


Table 3: Determinants of Parental Financial Transfers (Continued)

\begin{tabular}{|c|c|c|c|}
\hline Variables & OLS & $\begin{array}{c}\text { Family } \\
\text { Fixed-Effects }\end{array}$ & $\begin{array}{c}\text { Daughter } \\
\text { Fixed-Effects }\end{array}$ \\
\hline \multicolumn{4}{|l|}{ Panel C: } \\
\hline Teen birth & $\begin{array}{l}-.0481 * * \\
(.0236)\end{array}$ & $\begin{array}{l}-.0367 \\
(.0314)\end{array}$ & \\
\hline Teen birth $\times$ Black & $\begin{array}{l}.0472 * \\
(.0250)\end{array}$ & $\begin{array}{l}.0194 \\
(.0350)\end{array}$ & \\
\hline No. of sisters under 18 & $\begin{array}{l}.0225 * * * \\
(.0083)\end{array}$ & $\begin{array}{c}.0017 \\
(.0105)\end{array}$ & $\begin{array}{c}.0038 \\
(.0113)\end{array}$ \\
\hline No. of brothers under 18 & $\begin{array}{l}.0022 \\
(.0083)\end{array}$ & $\begin{array}{l}-.0179 \\
(.0111)\end{array}$ & $\begin{array}{l}-.0148 \\
(.0117)\end{array}$ \\
\hline No. of sisters under 18 with a teen birth, Non-black & $\begin{array}{l}-.0163 \\
(.0195)\end{array}$ & $\begin{array}{l}-.0168 \\
(.0246)\end{array}$ & $\begin{array}{l}-.0312 \\
(.0323)\end{array}$ \\
\hline No. of sisters under 18 with a teen birth, Black & $\begin{array}{l}-.0161 \\
(.0302)\end{array}$ & $\begin{array}{l}-.0350 \\
(.0333)\end{array}$ & $\begin{array}{l}-.0406 \\
(.0408)\end{array}$ \\
\hline Age-gap between daughter and her oldest sister under 18 & $\begin{array}{l}-.0022^{*} \\
(.0012)\end{array}$ & $\begin{array}{l}-.0002 \\
(.0017)\end{array}$ & $\begin{array}{l}.0009 \\
(.0019)\end{array}$ \\
\hline Age-gap between daughter and her oldest brother under 18 & $\begin{array}{l}-.0007 \\
(.0011)\end{array}$ & $\begin{array}{l}-.0011 \\
(.0017)\end{array}$ & $\begin{array}{c}.0016 \\
(.0020)\end{array}$ \\
\hline Teen birth $\times$ Sister age-gap & $\begin{array}{l}-.0012 \\
(.0053)\end{array}$ & $\begin{array}{c}.0001 \\
(.0071)\end{array}$ & $\begin{array}{l}-.0023 \\
(.0101)\end{array}$ \\
\hline Teen birth $\times$ Brother age-gap & $\begin{array}{c}.0054 \\
(.0035)\end{array}$ & $\begin{array}{l}.0059 \\
(.0041)\end{array}$ & $\begin{array}{l}.0041 \\
(.0058)\end{array}$ \\
\hline Teen birth $\times$ No. of sisters under 18 , Non-blacks & $\begin{array}{l}-.0813 * * \\
(.0330)\end{array}$ & $\begin{array}{l}-.0641 \\
(.0403)\end{array}$ & $\begin{array}{l}-.1121 * * \\
(.0562)\end{array}$ \\
\hline Teen birth $\times$ No. of sisters under 18 , Blacks & $\begin{array}{l}-.1045^{* * *} \\
(.0288)\end{array}$ & $\begin{array}{l}-.1071 * * * \\
(.0333)\end{array}$ & $\begin{array}{l}-.1015^{* *} \\
(.0444)\end{array}$ \\
\hline Teen birth $\times$ No. of sisters under $18 \times$ Sister age-gap & $\begin{array}{l}.0085^{*} \\
(.0048)\end{array}$ & $\begin{array}{l}.0057 \\
(.0061)\end{array}$ & $\begin{array}{l}.0080 \\
(.0098)\end{array}$ \\
\hline Teen birth $\times$ No. of brothers under 18 , Non-blacks & $-.1101 * * *$ & $\begin{array}{l}-.0959 * * \\
(0394)\end{array}$ & $\begin{array}{l}-.0669 \\
(0483)\end{array}$ \\
\hline Teen birth $\times$ No. of brothers under 18 , Blacks & $\begin{array}{l}(.0344) \\
-.1065 * * * \\
(.0242)\end{array}$ & $\begin{array}{l}-.0394) \\
(.0277)\end{array}$ & $\begin{array}{l}-.0485) \\
(.0317)\end{array}$ \\
\hline Teen birth $\times$ No. of brothers under $18 \times$ Brother age-gap & $\begin{array}{l}.0035 \\
(.0028)\end{array}$ & $\begin{array}{l}.0018 \\
(.0035)\end{array}$ & $\begin{array}{l}.0012 \\
(.0042)\end{array}$ \\
\hline Teen birth $\times$ No. sisters under $18 \times$ Family income & $\begin{array}{l}.0016 \\
(.0012)\end{array}$ & $\begin{array}{l}.0008 \\
(.0015)\end{array}$ & $\begin{array}{l}-.0003 \\
(.0021)\end{array}$ \\
\hline Teen birth $\times$ No. of sisters under 18 with a teen birth, Non-black & $\begin{array}{l}-.0579 \\
(.1042)\end{array}$ & $\begin{array}{l}-.2143^{*} \\
(.1280)\end{array}$ & $\begin{array}{l}-.3248 * \\
(.1916)\end{array}$ \\
\hline Teen Birth $\times$ No. of sisters under 18 with a teen birth, Black & $\begin{array}{l}-.0516 \\
(.0565)\end{array}$ & $\begin{array}{l}-.0009 \\
(.0635)\end{array}$ & $\begin{array}{l}-.0867 \\
(.0868)\end{array}$ \\
\hline $\begin{array}{l}\text { No. of Family or Individual Fixed Effects } \\
\text { No. of Observations }\end{array}$ & 13,618 & $\begin{array}{r}755 \\
13,618\end{array}$ & $\begin{array}{r}1,652 \\
13,618\end{array}$ \\
\hline
\end{tabular}

Notes: Financial transfer $=1$ if parents provide at least half of living expenses, $=0$ otherwise. In addition to variables listed above, OLS regressions control for family characteristics, such as parental age, family income in 1978, welfare status, parental education, parental attitude towards teen sex and total family size; daughter's characteristics, such as age, race, AFQT and other test scores; and contextual variables, such as living in central city, black and poverty proportion in the resident county, state AFDC benefits level and county employment growth rate. The fixed-effect regressions also control for such as parents' age, daughter's age, and time-varying contextual variables.

The highlighted areas display various marginal effects of the number of remaining daughters (or sons) on parental transfers.

$* p<0.10 ; * * p<0.05 ; * * * p<0.01$ 
Table 4: Determinants of Parental Co-Residence Transfers

[Dependent Variable: Whether Daughter lived with Parents at Age $t$; Sample: Families with 2-4 Daughters; Data Source: NLSY79]

\begin{tabular}{|c|c|c|c|}
\hline Variables & OLS & $\begin{array}{c}\text { Family } \\
\text { Fixed-Effects }\end{array}$ & $\begin{array}{c}\text { Daughter } \\
\text { Fixed-Effects }\end{array}$ \\
\hline \multicolumn{4}{|l|}{ Panel A: } \\
\hline Teen birth & $\begin{array}{l}-.0702 * * * \\
(.0184)\end{array}$ & $\begin{array}{l}-.0576 * * \\
(.0226)\end{array}$ & \\
\hline Teen birth $\times$ Black & $\begin{array}{l}.0349 * \\
(.0208)\end{array}$ & $\begin{array}{l}-.0302 \\
(.0269)\end{array}$ & \\
\hline No. of sisters under 18 & $\begin{array}{l}.0423 * * * \\
(.0083)\end{array}$ & $\begin{array}{l}.0294 * * * \\
(.0086)\end{array}$ & $\begin{array}{l}.0396 * * * \\
(.0083)\end{array}$ \\
\hline No. of brothers under 18 & $\begin{array}{l}.0307 * * * \\
(.0079)\end{array}$ & $\begin{array}{l}.0265 * * * \\
(.0085)\end{array}$ & $\begin{array}{l}.0255^{* * * *} \\
(.0081)\end{array}$ \\
\hline Age-gap between daughter and her oldest sister under 18 & $\begin{array}{l}-.0021 * \\
(.0012)\end{array}$ & $\begin{array}{l}-.0001 * * * \\
(.0014)\end{array}$ & $\begin{array}{l}-.0016 \\
(.0014)\end{array}$ \\
\hline Age-gap between daughter and her oldest brother under 18 & $\begin{array}{l}-.0047 * * * \\
(.0011)\end{array}$ & $\begin{array}{l}-.0044 * * * \\
(.0013)\end{array}$ & $\begin{array}{l}-.0048 * * * \\
(.0013)\end{array}$ \\
\hline Teen Birth $\times$ Sister age-gap & $\begin{array}{l}.0205^{* * * *} \\
(.0049)\end{array}$ & $\begin{array}{l}.0017 \\
(.0055)\end{array}$ & $\begin{array}{l}-.0006 \\
(.0062)\end{array}$ \\
\hline Teen Birth $\times$ No. sisters under 18 , Non-Blacks & $\begin{array}{l}-.0391 \\
(.0307)\end{array}$ & $\begin{array}{l}-.0941 * * * \\
(.0318)\end{array}$ & $\begin{array}{l}-.0816 * * \\
(.0348)\end{array}$ \\
\hline Teen Birth $\times$ No. sisters under 18, Blacks & $\begin{array}{l}-.0078 \\
(.0271)\end{array}$ & $\begin{array}{l}-.0463 * \\
(.0274)\end{array}$ & $\begin{array}{l}-.0396 \\
(.0297)\end{array}$ \\
\hline Teen Birth $\times$ No. sisters under $18 \times$ Sister age-gap & $\begin{array}{l}-.0149 * * * \\
(.0045)\end{array}$ & $\begin{array}{c}.0013 \\
(.0050)\end{array}$ & $\begin{array}{l}-.0015 \\
(.0063)\end{array}$ \\
\hline \multicolumn{4}{|l|}{ Panel B: } \\
\hline Teen birth & $\begin{array}{l}-.0811 * * * \\
(.0212)\end{array}$ & $\begin{array}{l}-.0624 * * \\
(.0261)\end{array}$ & \\
\hline Teen birth $\times$ Black & $\begin{array}{l}.0470 * * \\
(.0220)\end{array}$ & $\begin{array}{l}-.0258 \\
(.0281)\end{array}$ & \\
\hline No. of sisters under 18 & $\begin{array}{l}.0437 * * * \\
(.0090)\end{array}$ & $\begin{array}{l}.0227 * * \\
(.0094)\end{array}$ & $\begin{array}{l}.0291 * * * \\
(.0091)\end{array}$ \\
\hline No. of brothers under 18 & $\begin{array}{l}.0414 * * * \\
(.0092)\end{array}$ & $\begin{array}{l}.0297 * * * \\
(.0100)\end{array}$ & $\begin{array}{l}.0287 * * * \\
(.0097)\end{array}$ \\
\hline Age-gap between daughter and her oldest sister under 18 & $\begin{array}{l}-.0019 \\
(.0012)\end{array}$ & $\begin{array}{c}.0000 \\
(.0014)\end{array}$ & $\begin{array}{l}-.0016 \\
(.0014)\end{array}$ \\
\hline Age-gap between daughter and her oldest brother under 18 & $\begin{array}{l}-.0057 * * * \\
(.0012)\end{array}$ & $\begin{array}{l}-.0059 * * * \\
(.0014)\end{array}$ & $\begin{array}{l}-.0059 * * * \\
(.0015)\end{array}$ \\
\hline Teen birth $\times$ Sister age-gap & $\begin{array}{l}.0239 * * * \\
(.0052)\end{array}$ & $\begin{array}{l}.0010 * * \\
(.0057)\end{array}$ & $\begin{array}{l}.0006 \\
(.0065)\end{array}$ \\
\hline Teen birth $\times$ Brother age-gap & $\begin{array}{l}.0035 \\
(.0033)\end{array}$ & $\begin{array}{l}.0083 * * \\
(.0035)\end{array}$ & $\begin{array}{c}.0045 \\
(.0041)\end{array}$ \\
\hline Teen birth $\times$ No. of sisters under 18 , Non-blacks & $\begin{array}{l}-.0440 \\
(.0363)\end{array}$ & $\begin{array}{l}-.0784 * * \\
(.0379)\end{array}$ & $\begin{array}{l}-.0510 \\
(.0413)\end{array}$ \\
\hline Teen birth $\times$ No. of brothers under 18 , Blacks & $\begin{array}{l}-.0207 \\
(.0302)\end{array}$ & $\begin{array}{l}-.0408 \\
(.0309)\end{array}$ & $\begin{array}{l}-.0213 \\
(.0333)\end{array}$ \\
\hline Teen birth $\times$ No. of sisters under $18 \times$ Sister age-gap & $\begin{array}{l}-.0192 * * * \\
(.0048)\end{array}$ & $\begin{array}{l}-.0003 \\
(.0052)\end{array}$ & $\begin{array}{l}-.0041 \\
(.0065)\end{array}$ \\
\hline $\begin{array}{l}\text { Teen birth } \times \text { No. of brothers under } 18 \text {, Non-blacks } \\
\text { Teen birth } \times \text { No. of brothers under } 18 \text {, Blacks }\end{array}$ & $\begin{array}{l}-.0641^{*} \\
(.0376) \\
-.0555^{* *} \\
(.0265)\end{array}$ & $\begin{array}{l}-.0776 * * \\
(.0379) \\
-.0573 * * \\
(.0265)\end{array}$ & $\begin{array}{l}-.0900 * * \\
(.0390) \\
-.0567 * * \\
(.0271)\end{array}$ \\
\hline $\begin{array}{l}\text { Teen birth } \times \text { No. of brothers under } 18 \times \text { Brother age-gap } \\
\text { Teen birth } \times \text { No. of siblings under } 18 \times \text { Family income }\end{array}$ & $\begin{array}{l}.0072 * * * \\
(.0027) \\
.0004 \\
(.0013)\end{array}$ & $\begin{array}{c}.0021 \\
(.0031) \\
.0007 \\
(.0014)\end{array}$ & $\begin{array}{l}.0051 \\
(.0033) \\
-.0009 \\
(.0015)\end{array}$ \\
\hline
\end{tabular}


Table 4: Determinants of Parental Co-Residence Transfers (Continued)

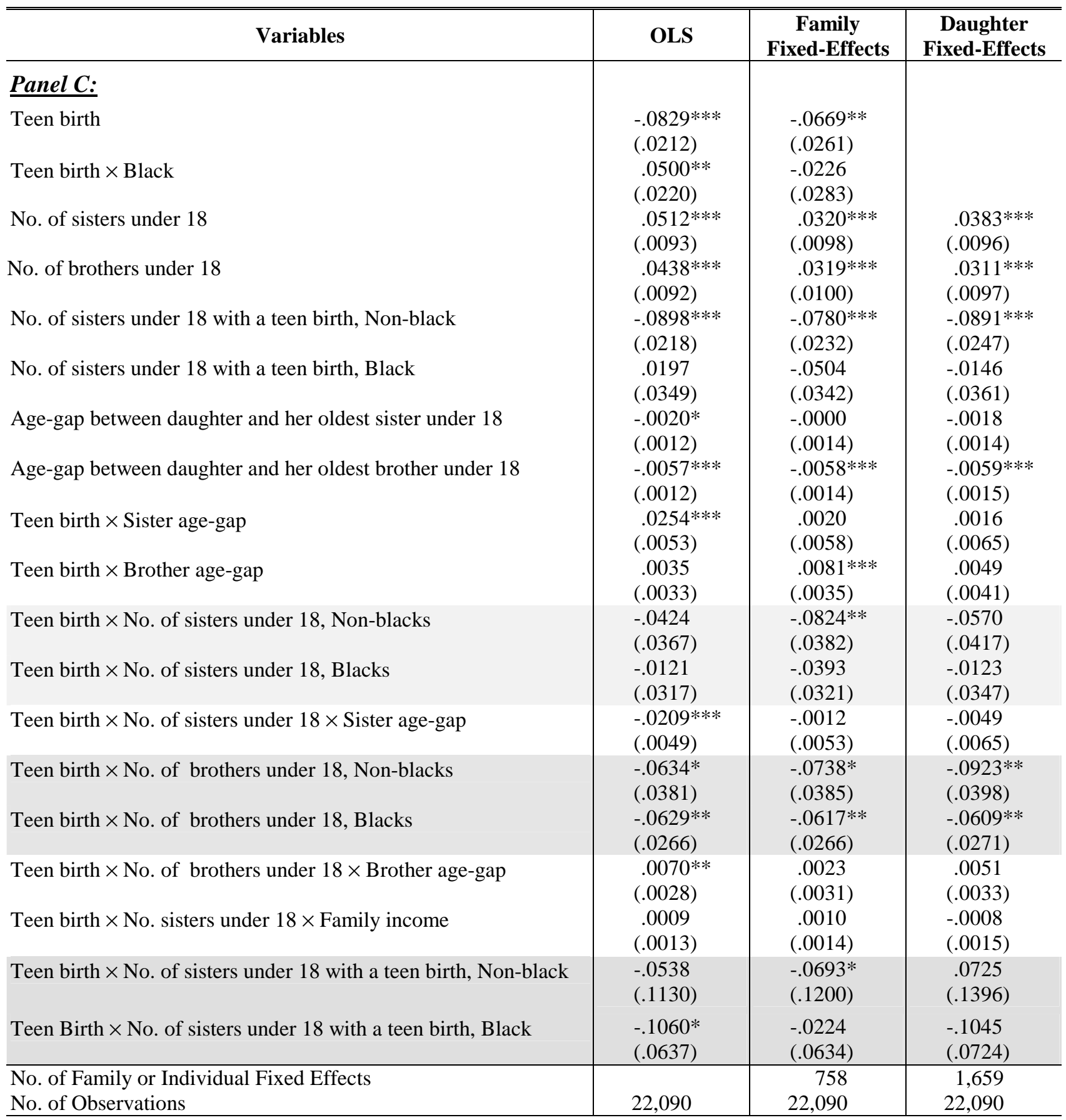

Notes: Coresidence $=1$ if the respondent lives with parents, $=0$ otherwise. In addition to variables listed above, OLS regressions control for family characteristics, such as parental age, family income in 1978, welfare status, parental education, parental attitude towards teen sex and total family size; daughter's characteristics, such as age, race, AFQT and other test scores; and contextual variables, such as living in central city, black and poverty proportion in the resident county, state AFDC benefits level and county employment growth rate. The fixed-effect regressions also control for such as parents' age, daughter's age, and time-varying contextual variables.

The highlighted areas display various marginal effects of the number of remaining daughters (or sons) on parental transfers.

$* p<0.10 ; * * p<0.05 ; * * * p<0.01$ 
Table 5: Determinants of Teenage Childbearing of Daughters

[Dependent Variable: Birth Prior to Age 18; Sample: Families with 2-4 Daughters; Data Source: NLSY79]

\begin{tabular}{|c|c|c|}
\hline Variables & OLS & $\begin{array}{c}\text { Family } \\
\text { Fixed-Effects }\end{array}$ \\
\hline \multicolumn{3}{|l|}{$\underline{\text { Panel } A}$} \\
\hline Number of children & $\begin{array}{c}.0030 \\
(.0029)\end{array}$ & $\begin{array}{l}.0091 \\
(.0073)\end{array}$ \\
\hline Age-gap between daughter and her oldest sister under 18 & $\begin{array}{l}.0013 \\
(.0049)\end{array}$ & $\begin{array}{l}.0084 \\
(.0065)\end{array}$ \\
\hline Age-gap between daughter and her oldest brother under 18 & $\begin{array}{l}.0013 \\
(.0040)\end{array}$ & $\begin{array}{l}.0132 * \\
(.0078)\end{array}$ \\
\hline No. of sisters under 18 , Non-blacks & $\begin{array}{l}-.0020 \\
(.0088)\end{array}$ & $\begin{array}{l}-.0060 \\
(.0151)\end{array}$ \\
\hline No. of sisters under 18 , Blacks & $\begin{array}{l}-.0060 \\
(.0097)\end{array}$ & $\begin{array}{l}-.0034 \\
(.0167)\end{array}$ \\
\hline No. of sisters under $18 \times$ Sister age-gap & $\begin{array}{l}-.0018 \\
(.0039)\end{array}$ & $\begin{array}{l}-.0112 \\
(.0053)\end{array}$ \\
\hline No. of brothers under 18 , Non-blacks & $\begin{array}{l}-.0071 \\
(.0104)\end{array}$ & $\begin{array}{l}.0063 \\
(.0246)\end{array}$ \\
\hline No. of brothers under 18 , Blacks & $\begin{array}{l}.0175 \\
(.0110)\end{array}$ & $\begin{array}{l}.0483^{*} \\
(.0257)\end{array}$ \\
\hline No. of brothers under $18 \times$ Brother age-gap & $\begin{array}{l}-.0010 \\
(.0038)\end{array}$ & $\begin{array}{l}-.0124^{*} \\
(.0066)\end{array}$ \\
\hline \multicolumn{3}{|l|}{ Panel B } \\
\hline Number of children & $\begin{array}{l}.0029 \\
(.0029)\end{array}$ & $\begin{array}{l}.0105 \\
(.0072)\end{array}$ \\
\hline Age-gap between daughter and her oldest sister under 18 & $\begin{array}{l}.0012 \\
(.0050)\end{array}$ & $\begin{array}{l}.0053 \\
(.0064)\end{array}$ \\
\hline Age-gap between daughter and her oldest brother under 18 & $\begin{array}{l}.0013 \\
(.0040)\end{array}$ & $\begin{array}{l}.0151^{* *} \\
(.0077)\end{array}$ \\
\hline No. of sisters under 18 , Non-blacks & $\begin{array}{l}-.0023 \\
(.0095)\end{array}$ & $\begin{array}{l}.0032 \\
(.0154)\end{array}$ \\
\hline No. of sisters under 18 , Blacks & $\begin{array}{l}-.0082 \\
(.0104)\end{array}$ & $\begin{array}{l}.0334^{*} \\
(.0181)\end{array}$ \\
\hline No. of sisters under $18 \times$ Sister age-gap & $\begin{array}{l}-.0015 \\
(.0041)\end{array}$ & $\begin{array}{l}-.0076 \\
(.0054)\end{array}$ \\
\hline No. of brothers under 18 , Non-blacks & $\begin{array}{l}-.0068 \\
(.0104)\end{array}$ & $\begin{array}{l}.0091 \\
(.0240)\end{array}$ \\
\hline No. of brothers under 18 , Blacks & $\begin{array}{l}.0176 \\
(.0110)\end{array}$ & $\begin{array}{l}.0397 \\
(.0253)\end{array}$ \\
\hline No. of brothers under $18 \times$ Brother age-gap & $\begin{array}{l}-.0011 \\
(.0038)\end{array}$ & $\begin{array}{l}-.0135^{* *} \\
(.0065)\end{array}$ \\
\hline No. of sisters under 18 with a teen birth, Non-black & $\begin{array}{c}.0024 \\
(.0227)\end{array}$ & $\begin{array}{l}-.0802 * * \\
(.0316)\end{array}$ \\
\hline No. of sisters under 18 with a teen birth, Black & $\begin{array}{l}.0139 \\
(.0230)\end{array}$ & $\begin{array}{l}-.1132 * * * \\
(.0308)\end{array}$ \\
\hline No. of sisters under 18 with a teen birth $\times$ age-gap & $\begin{array}{l}-.0015 \\
(.0068)\end{array}$ & $\begin{array}{l}-.0105 \\
(.0090)\end{array}$ \\
\hline $\begin{array}{l}\text { No. of Family Fixed Effects } \\
\text { No. of Individuals }\end{array}$ & 1,697 & $\begin{array}{r}782 \\
1,697 \\
\end{array}$ \\
\hline
\end{tabular}




\section{Table 5: Determinants of Teenage Childbearing of Daughters (continued)}

Notes: Both models include year and age dummy variables. The family fixed effects estimator excludes two daughters who belong to the same family but differ in race.

Both regressions also include the following control variables: Whether at least one biology sister is interviewed, biological parent's age, missing indicator for biological parent's age, mother's education, missing indicator for mother's education, father's education, missing indicator for father's education, parental family income in 1000's of 1978 dollars, missing indicator for parental family income, whether daughter was in an intact family at age 14, whether parents received AFDC in 1978, missing indicator for AFDC receipt, total number of siblings in daughter's family, total number of daughters in household, black dummy, AFQT score, missing indicator for AFQT score, measures of locus of control and selfesteem, whether living in central city, proportion of population black in county of residence, proportion of households living in poverty in county of residence, poverty $\times$ Central city interaction, AFDC benefit level (in \$1000) in state of residence, manufacturing employment growth rate in county of residence.

The highlighted areas display various marginal effects of the number of remaining daughters (or sons) on the incidence of teenage childbearing.

$* p<0.10 ; * * p<0.05 ; * * * p<0.01$ 


\section{Appendix A \\ Definitions of Variables used in Estimation of Teen Birth and Parental Transfer Equation Estimation}

In this Appendix, we describe how the explanatory variables used in the specifications of of (28) and (27). (The dependent variables for these equations are described in the text.)

Numbers of Sisters and Brothers Under 18:

Using the information contained in the questions on siblings of the NLSY79 respondents, which were gathered in a special module in the 1993 interview, we constructed variables for the number of sisters and brothers under age 18 at each age of the female respondent in question. These variables are age-variant; the two sources of variation are aging out (22\%) and new-born siblings $(0.6 \%)$. We also constructed variables for the number of sisters under 18 who had had a teen birth. To allow for differences in the effects by race, separate sets of variables are constructed for blacks and non-blacks, where non-blacks include whites and Hispanics.

Age-Gap Variables:

As noted in Section 2.2, we use the gap in ages between the $d^{\text {th }}$ daughter and her oldest sister (brother) under 18. Again, we construct these age-gap variables from the sibling questions implemented in the 1993 NLSY79 interview. The age-gap variables are measured by the year difference between the respondent and her oldest sister or brother who is under age 18, where if the oldest sibling under 18 is older than the respondent, we truncate the age-gap to 0 . If respondent is the only child in the family or if no more siblings are under age 18, the age-gap variable is set to zero. Separate variables were constructed for blacks and non-blacks.

\section{Measures of Prior Beliefs about Parents $\left(\pi_{N p}\right)$ :}

The other game theoretic predictor is daughters' prior belief about parents' type. In order to describe daughters' prior belief of parents' preference, we rely on information on attitudes toward teenage sex (a proxy of teenage childbearing) that were gathered in the General Social Survey (GSS). For the available 1,685 individuals born between 1929 and 1944 (drawn from GSS 1986-1992), we calculate the group means of attitudes toward teen sex by race, ethnicity, education, gender, and regional residence and then impute the value for NLSY79 women's parents using the group means. The original question is a 4-point scale (0-3) with the highest being the most liberal. The average scale for the socio-economic-regional groups is .79 to .1.29. We assume that our respondents observed the attitudes of other parents who resembled their own parents and formed the prior belief of their own parents' preference.

\section{Family Background and Daughter-Specific Characteristics and Contextual Variables:}

We have three blocks of control variables-family characteristics, individual characteristics and contextual conditions. Among the family characteristics, two variables are important controls for interpreting the estimated effect of the number of sisters (brothers) under 18, and the interaction of this variable with teen births, as reputation effects. First, we have the total number of children in the family at each age of the daughter to separate out the resource dilution effect 
from the reputation effect. Parents' financial resources may spread thin across a large number of children, compounding the parental reputation effects of a large number of sisters under age 18 . Second, we use parents' age to separate out the parents' life course effect from the reputation effect. When parents reach midlife and the peak of their earning profile, they have more resources to transfer to a daughter who had a teen birth. This may be particularly true for daughters who have fewer siblings under age 18 (implying also a smaller number of sisters under age 18). The set of variables describing parents' characteristics captures their preferences or tastes. Included in this set are the following variables: parents' education, family income, family structure and welfare receipt. The set of daughters' individual characteristics includes her age, race, ability, and psychological states, which influence both daughters and parents' decision. Finally, the set of variables describing the community conditions captures the economic and social environment within which the daughter and the parents make decisions. These include whether lived in central city; proportion of population in county of residence that are black, proportion of population in county of residence that live in poverty, and AFDC guarantee levels and employment growth rates in state of residence. 


\section{Appendix B: Comparison of Descriptive Statistics for Full Sample and Sister Sample: Variables Used in Financial Transfer Analysis}

\begin{tabular}{|c|c|c|c|c|}
\hline \multirow[b]{2}{*}{ Variable } & \multicolumn{2}{|c|}{ Full Sample } & \multicolumn{2}{|c|}{ Sister Sample } \\
\hline & Mean & $\begin{array}{l}\text { Standard } \\
\text { Deviation }\end{array}$ & Mean & $\begin{array}{l}\text { Standard } \\
\text { Deviation }\end{array}$ \\
\hline \multicolumn{5}{|l|}{ Dependent Variable } \\
\hline Parental financial transfers & .18 & .39 & .22 & .41 \\
\hline \multicolumn{5}{|l|}{ Variables used in Tests of Reputation Effects } \\
\hline Parents' attitudes toward teen sex & .41 & .20 & .42 & .20 \\
\hline Missing information on siblings & .11 & .31 & .08 & .27 \\
\hline Number of sisters under 18 & .22 & .54 & .28 & .59 \\
\hline Number of brothers under 18 & .23 & .56 & .25 & .56 \\
\hline Age-gap between daughter and her oldest sister under 18 & 1.36 & 3.46 & 1.61 & 3.60 \\
\hline Age-gap between daughter and her oldest brother under 18 & 1.43 & 3.50 & 1.65 & 3.74 \\
\hline Number of sisters under 18 already had a teen birth & .02 & .17 & .02 & .16 \\
\hline \multicolumn{5}{|l|}{ Family Characteristics } \\
\hline Parent's age & 50.94 & 12.12 & 51.56 & 7.41 \\
\hline Missing parent's age & .03 & .18 & .00 & .06 \\
\hline Mother's education & 11.24 & 3.29 & 11.64 & 2.76 \\
\hline Missing mother's education & .02 & .16 & .00 & .04 \\
\hline Father's education & 10.84 & 4.66 & 11.58 & 4.08 \\
\hline Missing father's education & .08 & .27 & .03 & .17 \\
\hline Intact family when respondent was 14 & .75 & .43 & .79 & .41 \\
\hline Parental family income in $1978(\$ 1,000)$ & 14.28 & 13.41 & 15.79 & 14.46 \\
\hline Missing parental family income & .18 & .39 & .21 & .41 \\
\hline Parents received AFDC in 1978 & .09 & .28 & .10 & .30 \\
\hline Missing AFDC receipt & .01 & .11 & .01 & .10 \\
\hline Number of children & 3.91 & 2.51 & 4.51 & 2.40 \\
\hline Missing number of children & .11 & .31 & .07 & .26 \\
\hline \multicolumn{5}{|l|}{ Individual Characteristics } \\
\hline Black & .14 & .35 & .16 & .37 \\
\hline Age & 23.89 & 3.07 & 23.50 & 2.95 \\
\hline AFQT & 53.90 & 30.15 & 55.75 & 31.09 \\
\hline Missing AFQT & .05 & .22 & .04 & .19 \\
\hline Locus of control & 2.86 & .62 & 2.85 & .58 \\
\hline Self-esteem & 3.16 & .66 & 3.17 & .61 \\
\hline Missing psychological state & .03 & .16 & .02 & .14 \\
\hline \multicolumn{5}{|l|}{ Contextual Conditions } \\
\hline Black proportion of resident county & .01 & .01 & .01 & .01 \\
\hline Poverty proportion of resident county & .01 & .01 & .01 & .01 \\
\hline Living in central city & .15 & .35 & .16 & .36 \\
\hline Poverty $\times$ Central city & 1.74 & 4.57 & 1.88 & 4.76 \\
\hline State AFDC benefit level $(\$ 1,000)$ & .45 & .18 & .46 & .18 \\
\hline Missing AFDC level & .00 & .00 & .00 & .00 \\
\hline County manufacturing employment growth rate & -.00 & .05 & -.00 & .05 \\
\hline Missing employment growth rate & .01 & .08 & .00 & .06 \\
\hline Number of families & 4,885 & & 755 & \\
\hline Number of individuals & 5,803 & & 1,652 & \\
\hline Number of observations & 48,387 & & 13,618 & \\
\hline
\end{tabular}

Note: Sampling weights were used to reproduce the population distribution of means and standard deviations. 